\title{
The Compatibility and Preparation of the Key Components for Cement and Asphalt Mortar in High-Speed Railway
}

\author{
Fazhou Wang and Yunpeng Liu \\ Wuhan University of Technology \\ China
}

\section{Introduction}

\subsection{Introduction of CA mortar for high-speed railway}

Slab track is a non-ballast track form that has found wide applications in high speed railways in countries like Japan, Germany, Spain and Italy due to its advantages of reduction in structure height, lower maintenance requirements, increased service life and high lateral track resistance which allows future speed increases (Harada Y TS, Itai N, 1976, 1983; Esveld C, 2003; Miura S et al, 1998). Also, China is witnessing a rapid expansion in developing high-speed railway to alleviate the increasing pressure of transferring people around such a big country (SH Jin 2006; JQ Zuo et al, 2005).

Nowadays, two main forms of Slab track (CRTS I, CRTS II) are used in China which evolve from Shinkansen slab track of Japan and Max-BÖgl slab track of Germany, respectively (Harada Y TS, Itai N, 1976; Esveld C,2003; Vogel W, 1995). There are some differences in slab structure as shown in Fig 1.

Cement and asphalt mortar (short for CA mortar, sometimes abbreviated to CAM) is an interlayer injected in the spaces between the track slab and the concrete roadbed (or hydraulically stabilized base), which is the key component in the structure of slab track. It mainly consists of cement matrix, asphalt emulsion, fine aggregates and a variety of admixtures (SG Hu et al, 2009a, 2009b; FZ Wang 2008, 2009, 2010). CA mortar used in CRTS I and CRTS II slab track are divided into I CAM and II CAM, respectively, whose physical and mechanical properties are shown in Table 1.

Due to the differences of slab track structure, the inject depth and properties of CAM (mainly are compressive strength and elastic modulus) are different. As for I-CAM used in CRTS-I slab track, the inject depth is about $50-70 \mathrm{~mm}$, the $28 \mathrm{~d}$ compressive strength is over $1.8 \mathrm{MPa}$ and elastic modulus is about $100-300 \mathrm{Mpa}$; however, as for II CAM used in CRTS-II slab track, the inject depth, $28 \mathrm{~d}$ compressive strength and elastic modulus are $20-40 \mathrm{~mm}$, over $15 \mathrm{Mpa}, 7000-10000 \mathrm{MPa}$, respectively. The mechanical properties, elastic modulus, durability of CA mortar determine the service life, safety and comfort of high speed railway. CA mortar is a new type of semi-rigid high performance composite material and possesses 
tremendous potential of applications in high speed railway which supports the track and train, adjusts the track precision and plays as shock absorber. Figures 2--5 showed the different status of CA mortar under construction.
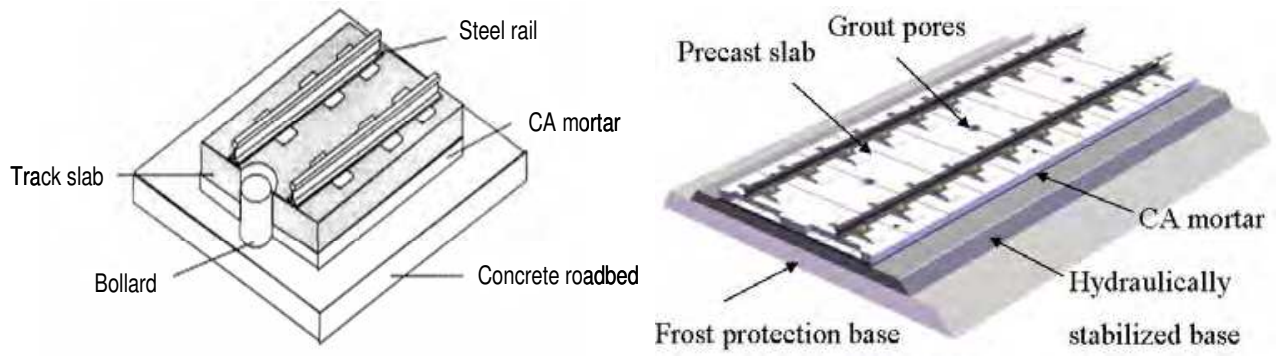

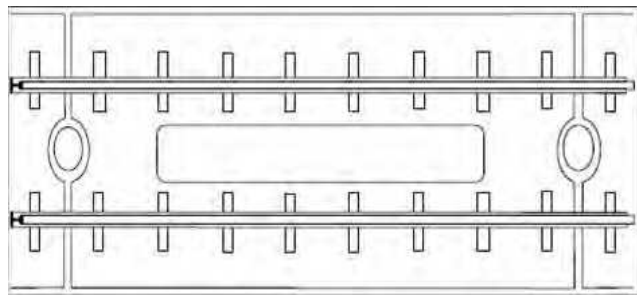

(a) Shinkansen slab track of Japan

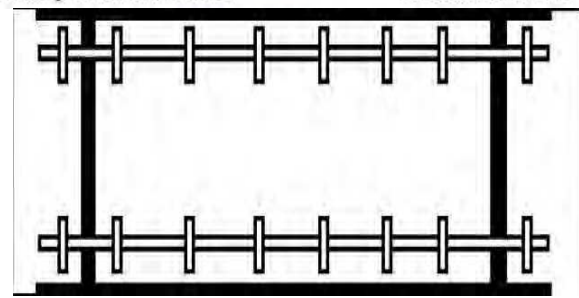

(b) Max-BÖgl slab track of Germany

Fig. 1. Structure of slab track

\begin{tabular}{lcc}
\hline & Composition & Performance \\
\hline \multirow{2}{*}{ I-CAM } & asphalt emulsion is cationic & Compressive strength $>1.8 \mathrm{MPa}$ \\
& $\mathrm{A} / \mathrm{C}^{*}$ is $1.4-1.6$ & elastic modulus 100-300MPa \\
II-CAM & asphalt emulsion is anionic & compressive strength $>15 \mathrm{MPa}$ \\
& $\mathrm{A} / \mathrm{C}$ is $0.3-0.4$ & elastic modulus $7-10 \mathrm{GPa}$ \\
\hline
\end{tabular}

Table 1. Comparison of I CAM and II CAM

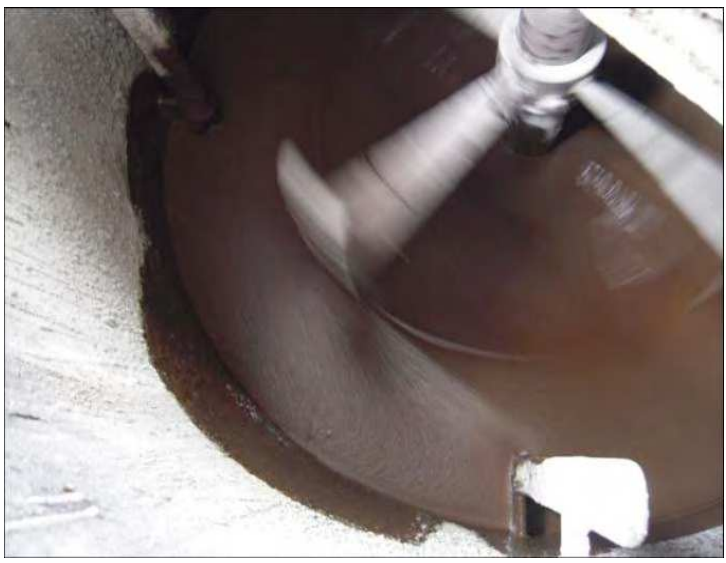

Fig. 2. Mix Process 
The Compatibility and Preparation of

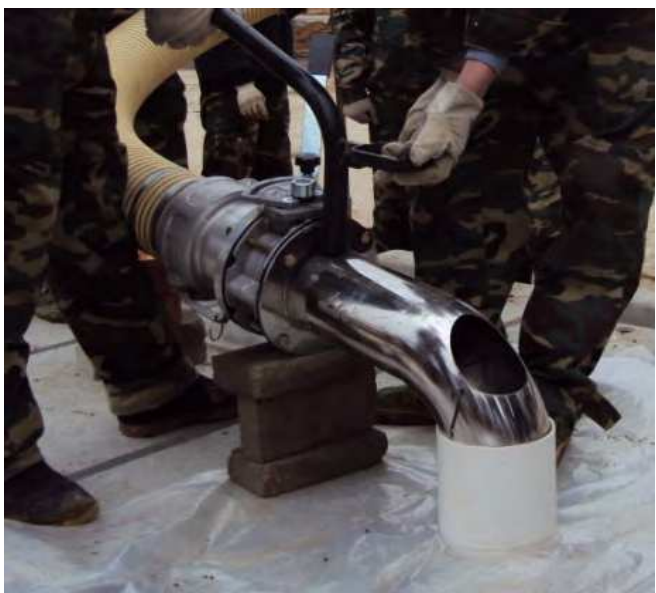

Fig. 3. Grouting Process

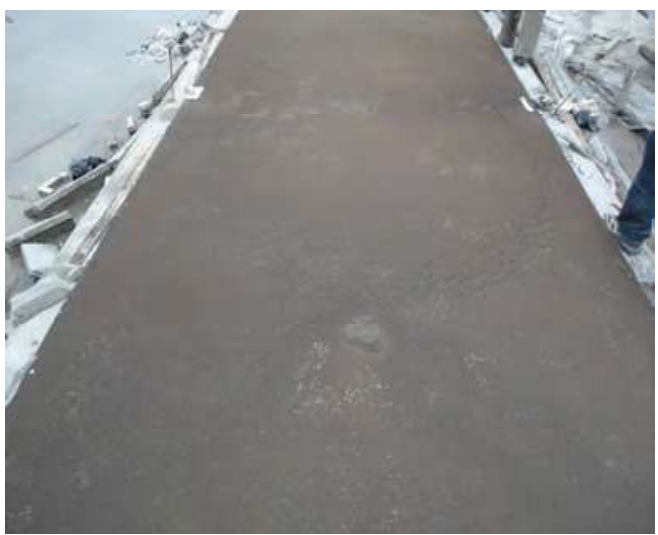

Fig. 4. Harden status

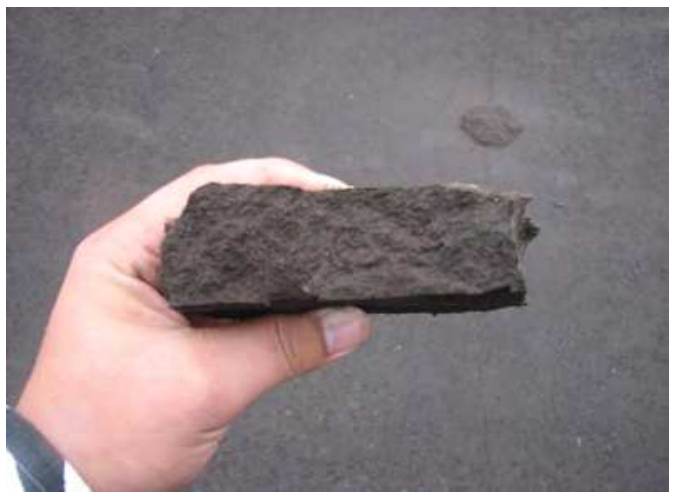

Fig. 5. Mortar Section 


\subsection{Hardening mechanisms of CAM}

The hardening process of CAM was the process that CA mortar changed from flow paste to hardening state, which included flow state, plastic state and hardening state. The experimental methods that investigated the different states were proposed. For example, the methods to evaluate the compatibility between cement and asphalt emulsion was proposed to investigate the early interaction between cement and emulsion; the particle size analyze technology was employed to characterize the particle size variation of cement-emulsion paste thus to study the adsorption behaviour of asphalt droplets to the cement grains. A filtration method was used to investigate the adsorption ratio of asphalt to the cement grains (SG Hu et al, 2009).

\subsubsection{The particle size analyze technology and filtration method}

The laser diffraction technique has been proven well applicable in the analysis of cement and polymer particles (Masood et al, 1994; Su,Z et al,1993) .A GSL-101 laser particle size analyzer with an analysis range of $0.15-400 \mu \mathrm{m}$ was used to test the particle size of the cement-asphalt emulsion (short for CAE) system. The given amounts of cement and asphalt emulsion were weighed and thoroughly mixed, then a representative sample was taken for test. The testing procedure was completed within $150 \mathrm{~s}$. The variation of particle size D90 in the CAE system (droplet diameter for the 90th cumulative mass percentile) was obtained. The results were shown in Table 2.

\begin{tabular}{lcccc}
\hline \multirow{2}{*}{ Time/particle size } & \multicolumn{4}{c}{ Cement: Asphalt emulsion (C:A) } \\
\cline { 2 - 5 } & $0: 1$ & $0.4: 1$ & $0.625: 1$ & $1: 1$ \\
\hline $0 \mathrm{~min} / \mu \mathrm{m}$ & 2.61 & 9.86 & 13.14 & 14.84 \\
$15 \mathrm{~min} / \mu \mathrm{m}$ & 2.61 & 13.26 & 18.31 & 20.16 \\
$30 \mathrm{~min} / \mu \mathrm{m}$ & 2.61 & 16.95 & 24.85 & 28.64 \\
$60 \mathrm{~min} / \mu \mathrm{m}$ & 2.61 & 18.84 & 29.48 & 33.73 \\
\hline
\end{tabular}

Table 2. Particle size variation of CAE system with different $\mathrm{A} / \mathrm{C}$ ratio

As can be seen from Table2, the cement content played a significant influence on the particle variations of CAE system. When there was on cement in the paste, the initial emulsion particle size was $2.61 \mu \mathrm{m}$ and was constant with time. With the increase of cement content, the particle size of CAE system increased with time. When $\mathrm{A} / \mathrm{C}=0.41$, the particle size of CAE paste increased by $34.5 \%, 71.9 \%$ and $91.1 \%$, respectively, compared to the initial particle size, within the periods of 15,30 and $60 \mathrm{~min}$; with $\mathrm{A} / \mathrm{C}=0.625$ the percentages were $35.5 \%, 89.1 \%$ and $124.4 \%$, respectively and with $\mathrm{A} / \mathrm{C}=1$, were $35.8 \%, 93 \%$ and $127.3 \%$, respectively. The results indicated that the presence of cement in the CAE system accelerated the breaking of the asphalt emulsion, or the adsorption of the asphalt droplets to cement grains, both of which could be responsible for the particle size increase.

On the other hand, the increasing magnitudes within the corresponding periods increased with the presence of cement. Within the same time periods, the particle size increased more prominently with a larger $\mathrm{C} / \mathrm{AE}$. The particle size variation of CAE system with $\mathrm{C} / \mathrm{AE}$ of 0.625 and 1.0 exhibited an analogous increasing magnitude within the periods of 30 and 60 min, and were both greater than that with C/AE of 0.4, which indicated that when $\mathrm{C} / \mathrm{AE}$ was larger than 0.625 , the cement content had only a slight influence on the increasing magnitude of particle size of CAE system after $30 \mathrm{~min}$. 
The filtration method to evaluate the adsorption ratio of asphalt droplets to cement grains was as follows: first, the cement and asphalt emulsion were filtrated through the $45 \mu \mathrm{m}$ sieve; the cement retained on the sieve and asphalt emulsion passed the sieve were used for the tests; the cement and asphalt emulsion were mixed thoroughly and then the testing sample was diluted with distilled water and then filtered through the sieve, the residue was put in an oven until the weight of residue was constant. The adsorption ratio that asphalt droplets to cement grains was calculated as equation 1 and the results were shown in Table 3.

$$
v=\frac{m_{2}-m_{0}}{m_{1}} \times 100 \%
$$

Where $\mathrm{V}$ is the adsorption ratio(\%); $\mathrm{m}_{0}$ is the cement content before mixing (\%); $\mathrm{m}_{1}$ is the asphalt content in the emulsion before mixing (g); and $\mathrm{m}_{2}$ is the residues of cement and asphalt retained on $45 \mu \mathrm{m}$ sieve after mixing $(\mathrm{g})$.

\begin{tabular}{lccc}
\hline \multirow{2}{*}{ Time } & \multicolumn{3}{c}{ Cement: Asphalt emulsion(C:A) } \\
\cline { 2 - 4 } & $0.4: 1$ & $0.625: 1$ & $1: 1$ \\
\hline 0min/ Adsorption ratio & 7.8 & 10.5 & 14.3 \\
15min/ Adsorption ratio & 12.0 & 16.9 & 19.6 \\
30min/ Adsorption ratio & 19.1 & 24.4 & 27.5 \\
60min/ Adsorption ratio & 39.9 & 50.1 & 56.8 \\
\hline
\end{tabular}

Table 3. Adsorption ratios in CAE system with different $\mathrm{A} / \mathrm{C}$ ratio

As can be seen from Table 3, the cement presented a significant adsorption effect on the asphalt droplets to cement grains within a period of $60 \mathrm{~min}$ and the adsorption ratio increased with the time. When $\mathrm{C} / \mathrm{AE}$ was 0.4 , the adsorption ratios were increased by 4.2 , 11.3 and $32.1 \%$, respectively, within the periods of 15,30 and $60 \mathrm{~min}$, compared to the initial adsorption ratio. When $\mathrm{C} / \mathrm{AE}$ was 1.0, the corresponding increasing percentages were $5.3,13.2$ and $42.5 \%$, respectively. The adsorption ratio varied with the A/C ratio and increased with the cement contents. The increasing trend in adsorption ratio was analogous to that in particle size, which indicated that the particle size increase in the CAE system was mainly attributed to the adsorption behaviour of asphalt droplets to cement grains.

\subsubsection{Non-contact resistivity}

The resistivity of hardening-CAM with time was measured with CCR2 non-contact resistivity measuring instrument to investigate the evolution mechanism of CA mortar from flow state to hardening structure. CAM was prepared according to a certain ratio, then the fresh paste was poured into the mold and the resistivity was recorded every minute to get the resistivity-time curve. The ambient temperature was $20 \pm 1^{\circ} \mathrm{C}$ and the results were shown in Fig6. 


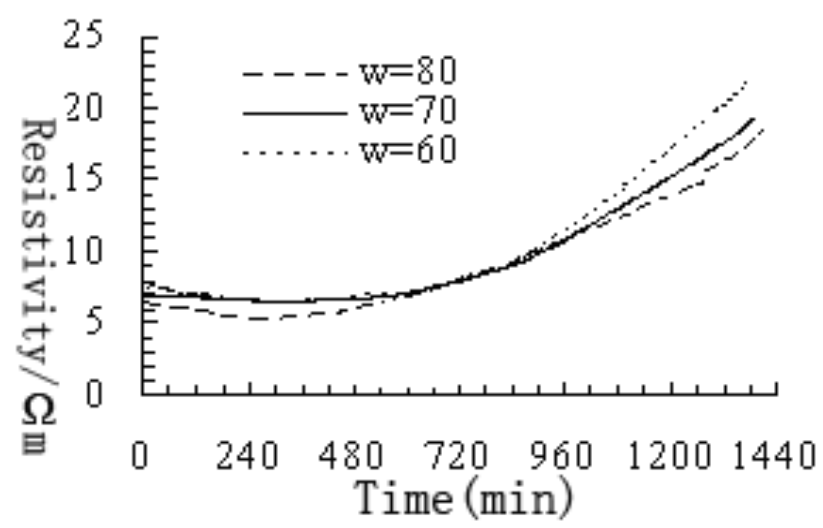

Fig. 6. Resistivity-time curve of CAM with different A/C ratio

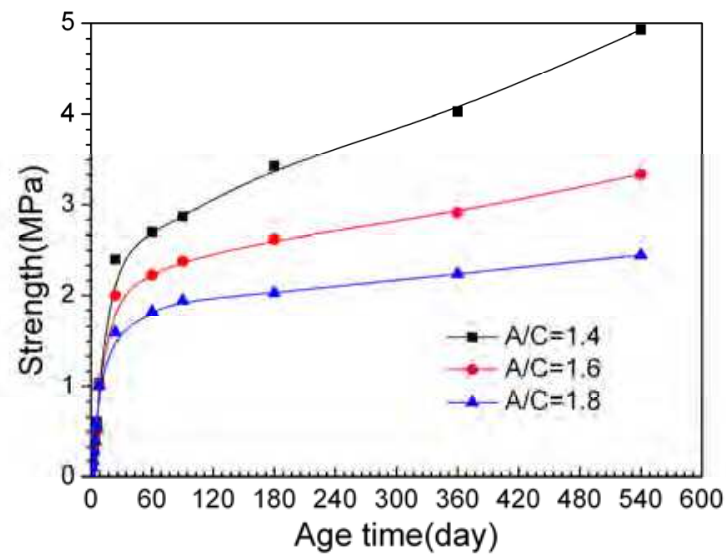

Fig. 7. CAM Strength development with age time

As can be seen from Fig6, the CAM resistivity was stable when CAM was under flow state and plastic state; also CAM with different water content presented the same trend. The resistivity decreased with the increase of water content, which indicated the ionic channel in the structure increased and the density decreased.

\subsubsection{Strength development of hardening CAM}

In the structure development of CAM, the asphalt droplets formed an asphalt net film in the CAM after emulsion breaking. However, the cement grains hydrated out-in and the cement grains would be coated with the hydration product formed before, thus the hydration of cement grains inside would be retarded. When asphalt emulsion broke and formed an asphalt film, the cement continued to hydrate which consumed the water inside and increased the solid contents. The density of CAM increased and lead to a continue increase of strength. The mix proportion and experimental results are shown in Table4 and Fig7, respectively. 
The Compatibility and Preparation of

\begin{tabular}{lcccc}
\hline Number & $\mathrm{A} /(\mathrm{C}+\mathrm{UEA})$ & $\mathrm{A} / \mathrm{kg} \mathrm{m}^{-3}$ & $\mathrm{C} / \mathrm{kg} \mathrm{m}^{-3}$ & $\mathrm{~W} / \mathrm{kg} \mathrm{m}^{-3}$ \\
\hline Y1 & 1.5 & 450 & 255 & 80 \\
L2 & 1.6 & 480 & 255 & 70 \\
Y2 & 1.7 & 510 & 255 & 60 \\
\hline
\end{tabular}

Table 4. Mix proportion of CA mortar

As shown in Fig7, the CAM strength increased with the age time. The increase magnitude varied with different $\mathrm{A} / \mathrm{C}$ ratio and increased with cement content. When the $\mathrm{A} / \mathrm{C}$ ratio was 1.4, 1.6 and 1.8, the increase percentages of CAM strength within 180days compared to that within 28 days were $41 \%, 30 \%$ and $25 \%$, respectively; and that within 540days were $93 \%$, $65 \%, 47 \%$, respectively. This indicated that the cement in CAM continued to hydrate with age time, but the hydrate degree of later stage decreased, also were the increase percentages of CAM strength.

The elastic modulus of I-CAM and II-CAM were about $100-300 \mathrm{Mpa}$ and 7000$10000 \mathrm{Mpa}$, respectively, according to the standard requirements. However, the CAM strength of later stage was not considered in the standard. The mechanic properties (strength and elastic modulus) variations with age time were investigated as shown in Table 5. As can be seen, the average increase percentages of CAM strength and elastic modulus between 20days and 120days were $6.8 \% \sim 17.7 \%$ and $7.0 \sim 8.5 \%$, respectively. Thus, the increase of elastic modulus should be considered in the CAM design to ensure the long-term mechanic properties.

\begin{tabular}{lccccccc}
\hline $\begin{array}{l}\text { Dry } \\
\text { blend }\end{array}$ & $\begin{array}{c}\text { Density/kg } \\
\mathrm{m}^{-3}\end{array}$ & $\begin{array}{c}1 \mathrm{~d} \\
\text { strength } \\
/ \mathrm{MPa}\end{array}$ & $\begin{array}{c}7 \mathrm{~d} \\
\text { strength } \\
/ \mathrm{MPa}\end{array}$ & $\begin{array}{c}28 \mathrm{~d} \\
\text { strength/ } \\
\mathrm{MPa}\end{array}$ & $\begin{array}{c}120 \mathrm{~d} \\
\text { strength } \\
/ \mathrm{MPa}\end{array}$ & $\begin{array}{c}28 \mathrm{~d} \text { elastic } \\
\text { modulus } \\
/ \mathrm{MPa}\end{array}$ & $\begin{array}{c}120 \mathrm{~d} \\
\text { elastic } \\
\text { modulus } \\
/ \mathrm{MPa}\end{array}$ \\
\hline JS & 1940 & 3.1 & 14.0 & 18.1 & 21.3 & 8875 & 9500 \\
$\mathrm{DM}$ & 1900 & 3.3 & 12.2 & 20.1 & 22.4 & 8072 & 9044 \\
$\mathrm{MK}$ & 1950 & 3.3 & 15.2 & 19.1 & 21.8 & 9251 & 9953 \\
ZY & 2010 & 3.2 & 15.5 & 22.0 & 23.5 & 9075 & 9845 \\
\hline
\end{tabular}

Table 5. Mechanic properties of CAM with different dry blend

\subsection{Structure development of CAM}

As mentioned before, the CAM hardening process was the process that CAM changed from flow paste to harden mortar, which included flow state, plastic state and hardening state. Moreover, the process could be divided into four states which included the dispersion state, the interaction between cement and asphalt emulsion, the formation of asphalt net structure and structure development of harden mortar. 


\subsubsection{Dispersion state}

The cement grains and emulsion droplets dispersed isolately in the fresh cement-asphalt emulsion paste as shown in Fig 8.

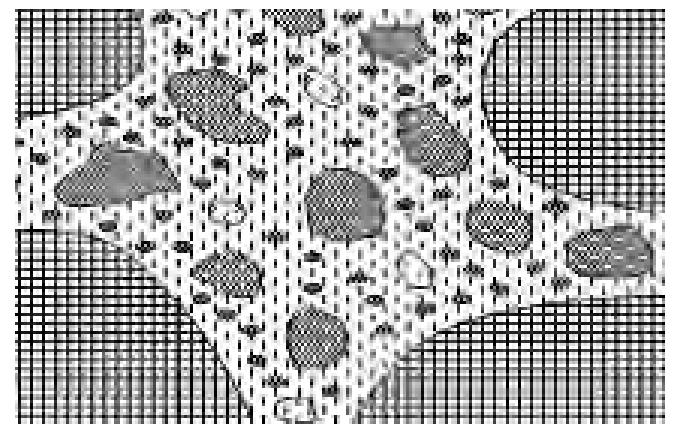

Fig. 8. Dispersion state

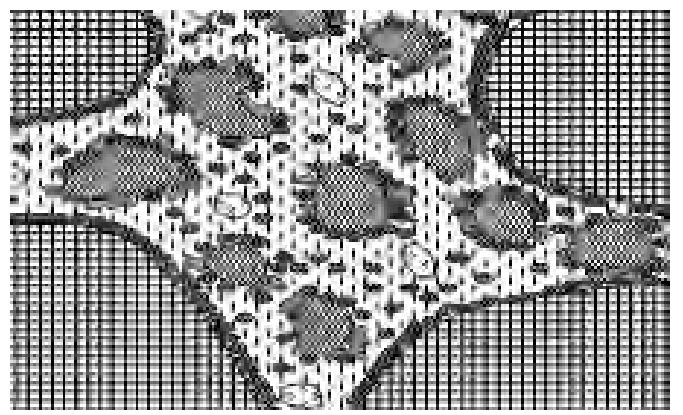

Fig. 9. Interaction between cement and emulsion

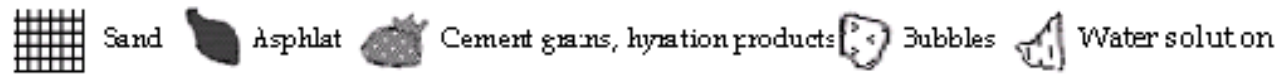

\subsubsection{Interaction between cement hydration and emulsion breaking}

The hydration product gradually formed when the $\mathrm{Ca}(\mathrm{OH})_{2}$ concentration was saturated after the $\mathrm{Ca}(\mathrm{OH})_{2}$ induced by cement hydration neutralized the acid in asphalt emulsion. Meanwhile, asphalt droplets would absorb to the cement grains and cement hydration product. The dispersion state turned to the interaction between cement hydration and asphalt emulsion breaking. (Fig9)

\subsubsection{Formation of asphalt net structure}

The cement hydration consumed much free water and decreased the distance between asphalt droplets which made droplets easy to contact and finally formed a continuous asphalt film. This process was within $20 \mathrm{~h}$ and the asphalt net film contacted with the cement hydration products to form the harden mortar structure. (Fig10) 


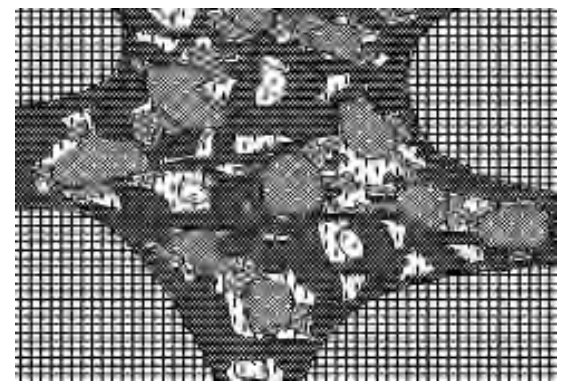

Fig. 10. Formation of asphalt net structure

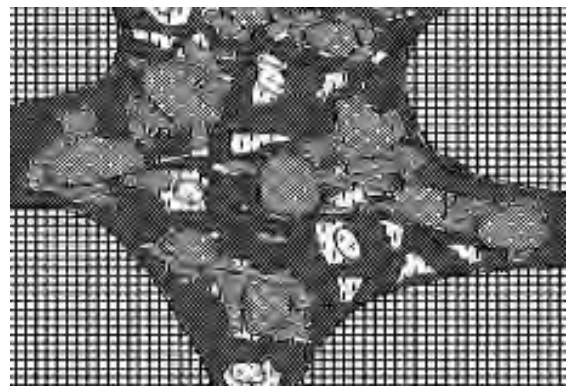

Fig. 11. Harden mortar structure development

\subsubsection{Harden mortar structure development}

After the emulsion broke and the asphalt net film formed, much water and cement grains were contained in the film, which would influence the mechanic properties of CAM. The cement grains surface would absorb the asphalt droplets selectively, some parts of the surface contacted with asphalt while other parts contacted with water, thus promoted the cement hydration and increased the solid contents. The density of CAM increased gradually and the strength increased with age time. However, the CAM strength of later stage increased slowly because of the retard effect of asphalt film on the contact between cement grains and water (Fig11).

\section{Compatibility between raw materials}

CAM is mainly consisted of dry blend which is mainly composed of cement, expansive agent, sand and some minor components for properties adjustment, asphalt emulsion, water, superplasticizer and anti-foaming agents. Of which cement and asphalt emulsion are the main components of CAM. However, the cement hydration and emulsion breaking are affected by each other and influenced the CAM's properties. The cement content determines the CAM's strength and elasticity, also the cement hydration influences the emulsion breaking, thus the organic and inorganic materials should have a proper ratio which means the cement hydration rate should match the emulsion breaking rate. These tough requirements for the match of proportion, hydration rate and breaking speed are named compatibility. 
The setting process of cement and asphalt emulsion paste (CAE) is of great importance on the properties of CA mortar, which requires a proper match between the two materials, namely an optimum cement/asphalt emulsion ratio (C/AE ratio) and the coordinated and compatible rate between the hydration of cement and the breaking of asphalt emulsion, which is vital to the homogeneity of CA mortar. In this chapter, the setting process of CAE was characterized by that of the paste prepared with cement and asphalt emulsion. The influences of cement types (two ordinary Portland cements and one sulfoaluminate cement), $\mathrm{C} / \mathrm{AE}$ ratios $(0.6,1.0,1.6$, and 2.0) and blended cement on the setting process of the paste and on the properties of CA mortar were investigated.

A new method to evaluate the setting process of cement and asphalt emulsion in CA mortar was proposed (FZ Wang, 2008). The method was developed from the standard specification for the test of setting time of cement paste (GB/T 1346-2001). The cement-asphalt emulsion paste was prepared in a mould, then every $30 \mathrm{~min}$, a steel needle penetrated the grout from the upper surface and after $30 \mathrm{~s}$ a depth was read. The setting process could be characterized by plotting the depth against time. The time of first catastrophe point was defined as the initial setting time and the time when the depth plotted was stable was defined as the final setting time.

\subsection{Influence of cement types on the setting process of CAE in CA mortar}

Cement: three types of cements (C1, C2 and C3) were used, among which C1 and C2 were ordinary Portland cements and C3 was rapid hardening sulfoaluminate cement. The properties of the three cements were listed in Table6.

\begin{tabular}{lcccccc}
\hline \multirow{2}{*}{ Cement } & $\begin{array}{c}\text { Surface density } \\
\mathrm{g} / \mathrm{cm}^{3}\end{array}$ & \multicolumn{2}{c}{ Setting time /min } & \multicolumn{3}{c}{ Compressive strength / MPa } \\
\cline { 3 - 6 } & 3.13 & 138 & 190 & 17.7 & 22.9 & 47.3 \\
\hline $\mathrm{C} 1$ & 3.18 & 131 & 170 & 13.0 & 21.3 & 46.5 \\
$\mathrm{C} 2$ & 2.79 & 29 & 50 & 38.4 & 46.7 & 50.3 \\
$\mathrm{C} 3$ & & & &
\end{tabular}

Table 6. Physical properties of cements

Sand: River sands S2, S3 and S4 with fineness modulus of 1.4, 1.7 and 2.0, respectively. The properties were shown in Table7.

\begin{tabular}{c|c|c|c|c|c}
\hline Number & Properties & Results & Number & Properties & Results \\
\hline 1 & Bulk density $\left(\mathrm{kg} / \mathrm{m}^{3}\right)$ & 1380 & 4 & Mud content $(\%)$ & 0.3 \\
2 & Packing density $\left(\mathrm{kg} / \mathrm{m}^{3}\right)$ & 1480 & 5 & Mica content $(\%)$ & 0.6 \\
3 & Apparent density $\left(\mathrm{kg} / \mathrm{m}^{3}\right)$ & 2630 & 6 & Organic content $(\%)$ & Qualified \\
\hline
\end{tabular}

Table 7. Properties of river sand

Expansion agent: Aluminum powder (AP) was Flaky and its properties were given in Table 8. UEA expansive agent for cement, the properties are shown in Table9. 


\begin{tabular}{cc}
\hline Appearance & Silvery white \\
\hline Purity $(\%)$ & $\geq 99.0$ \\
Soluble organic substance $(\%)$ & $\leq 4.0$ \\
Volatiles $\left(105^{\circ} \mathrm{C} \%\right)$ & $\leq 10.0$ \\
Particle size $(\mathrm{m})$ & $50-75$ \\
Solubility & Soluble in acid, alkali, not in water \\
\hline
\end{tabular}

Table 8. Specifications of aluminum powder

\begin{tabular}{|c|c|c|c|c|c|c|c|}
\hline $\begin{array}{c}\text { Num } \\
\text { ber }\end{array}$ & & Properties & $\underset{\mathrm{s}}{\operatorname{Result}}$ & $\begin{array}{c}\text { Num } \\
\text { ber }\end{array}$ & \multicolumn{2}{|c|}{ Properties } & $\underset{\mathrm{S}}{\text { Result }}$ \\
\hline \multirow{2}{*}{1} & \multirow{2}{*}{$\begin{array}{l}\text { Finen } \\
\text { ess }\end{array}$} & $\begin{array}{c}\text { Material retained } \\
\text { on sieve } 0.08 \mathrm{~mm}\end{array}$ & 2.0 & 3 & \multicolumn{2}{|c|}{ Density (kg/m3) } & 2750 \\
\hline & & $\begin{array}{c}\text { Material retained } \\
\text { on sieve } 1.25 \mathrm{~mm} \\
(\%)\end{array}$ & 0 & \multirow{2}{*}{4} & \multirow{2}{*}{$\begin{array}{l}\text { Limited } \\
\text { expan- } \\
\text { sion ratio }\end{array}$} & $\begin{array}{c}\text { In water } 14 \mathrm{~d} \\
(\%)\end{array}$ & 0.03 \\
\hline 2 & \multicolumn{2}{|c|}{$\mathrm{MgO}$ contents (\%) } & 1.7 & & & $\begin{array}{c}\text { In air } 28 \mathrm{~d} \\
(\%)\end{array}$ & -0.013 \\
\hline
\end{tabular}

Table 9. Properties of UEA expansive agent

Polycarboxylate-based superplasticizer (SP)

Defoamer: silicone type.

Asphalt emulsion: Independent development and manufacture.

The influences of cements C1, C2 and C3 on the cement-asphalt emulsion paste setting time were shown in Fig12.

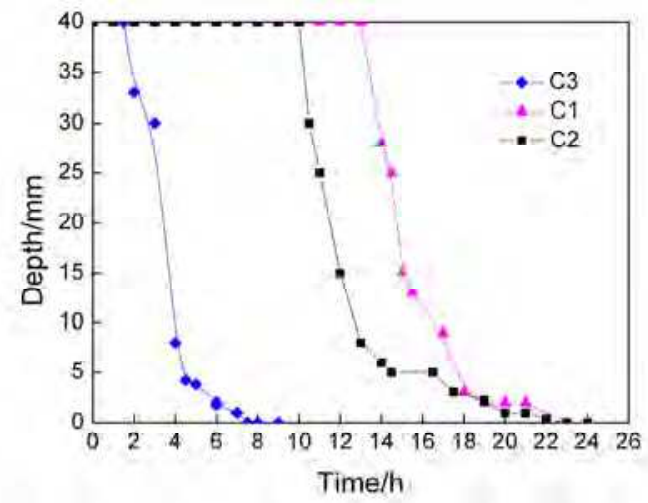

Fig. 12. Influences of cements on the setting process of CAE paste 


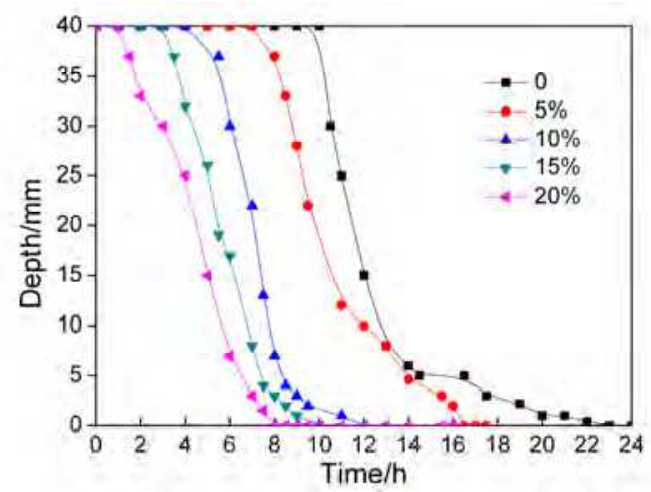

Fig. 13. Influences of blending cements on the setting process of CAE paste

As indicated in Fig.13, the setting process of CAE3 (C3 was used) was the fastest with the initial setting time of less than $2 \mathrm{~h}$ and final setting time of $9 \mathrm{~h}$. The CAE1 (C1 was used) and CAE2 (C2 was used) had a slower setting time, with the initial time of 11, 13h and final setting time of $21,23 \mathrm{~h}$, respectively.

\begin{tabular}{lccccccc}
\hline & & \multirow{2}{*}{$\begin{array}{c}\text { Separation rate } \\
\text { No. }\end{array}$} & Cements & $\begin{array}{c}\text { Fluidity } \\
\text { / }\end{array}$ & $\begin{array}{c}\text { Workable time } \\
/ \text { min }\end{array}$ & \multicolumn{3}{c}{$\begin{array}{c}\text { Compressive strength } \\
\text { /MPa }\end{array}$} \\
\hline CAM1 & C1 & 0.6 & 20 & 70 & 0.14 & 0.88 & 2.0 \\
CAM2 & C2 & 0.7 & 19.5 & 85 & 0.13 & 0.85 & 2.1 \\
CAM3 & C3 & 0.5 & 19.5 & 35 & 0.82 & 1.8 & 2.0 \\
\hline
\end{tabular}

Table 10. Properties of CA mortar prepared with different cements

As can be seen from Table10, the cements played a significant effect on the CAM's workable time and strength. The workable time of CAM3 was only 35min while that of CAM1 and CAM2 were as long as 70 and $85 \mathrm{~min}$, respectively. However, the $1 \mathrm{~d}$ and $7 \mathrm{~d}$ strength of CAM3 were 0.82 and $1.8 \mathrm{Mpa}$, which was quite higher than that of CAM1 and CAM2. The properties of CAM 1 and CAM2 were quite similar except the difference in early strength.

The influences of blending cements on the CAM properties were also investigated. In this test, blended cements with different combinations of $\mathrm{C} 1$ and $\mathrm{C} 3$ were used, and $\mathrm{C} 1$ was replaced by $\mathrm{C} 3$ with different replacement ratios $(0 \%, 5 \%, 10 \%, 15 \%$, and $20 \%)$. Results were given in Fig.13.

As indicated in Fig.13, the setting process of a blended cement-asphalt emulsion system was markedly accelerated compared to that using $\mathrm{C} 1$ only, and the accelerating effect was more obvious with the higher the replacement ratio. When the replacement ratio exceeded $20 \%$, the paste had an early initial setting time of less than $2 \mathrm{~h}$ and final setting time of $9 \mathrm{~h}$ compared to $11 \mathrm{~h}$ and $21 \mathrm{~h}$ of the paste using $\mathrm{C} 1$. So the emulsion breaking and CAE paste setting could be well controlled with the blending cement to have a proper harden time and prevent the early bleeding of CA mortar. 


\subsection{Influence of C/AE ratios on the setting process of CAE in CA mortar}

The $\mathrm{C} / \mathrm{AE}$ ratio is the key factor that influences the setting process of CAM. The influence of $\mathrm{C} / \mathrm{AE}$ ratio on the setting process was studied with four $\mathrm{C} / \mathrm{AE}$ ratios $(0.6,1.0,1.6$, and 2.0$)$ and cement $\mathrm{C} 1$ used. The results were shown in Fig. 14.

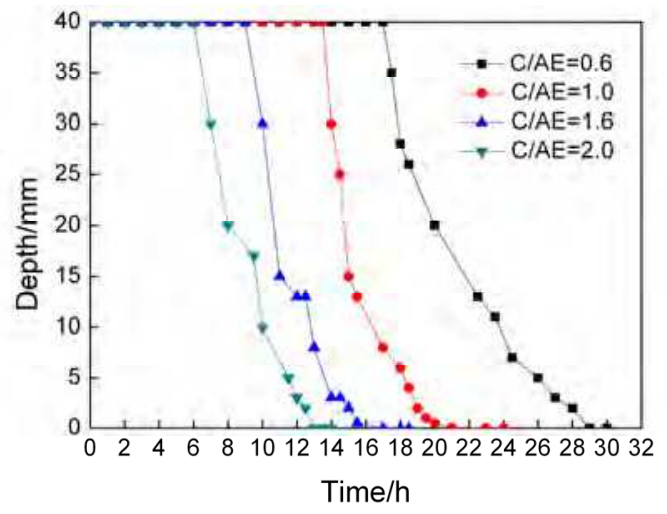

Fig. 14. Influence of $\mathrm{C} / \mathrm{AE}$ ratio on the setting process of CAE paste

As can be seen from Fig14, the setting process of $\mathrm{CAE}$ was slowed with the decrease of $\mathrm{C} / \mathrm{AE}$ ratio. The higher $\mathrm{C} / \mathrm{AE}$ ratio with more cements lead to a quicker setting process. When $\mathrm{C} / \mathrm{AE}$ ratio was 2.0, the final setting time of CAE was about $15 \mathrm{~h}$, while that of $\mathrm{C} / \mathrm{AE}$ ratio 0.6 was as long as $26 \mathrm{~h}$. So, the setting process of CAE was directly proportional to the cement content. The cement hydration promoted the emulsion breaking and was benefit to the paste hardening.

\begin{tabular}{lccccccc}
\hline \multirow{2}{*}{ No. } & A/C & Fluidity/s & $\begin{array}{c}\text { Workable time } \\
\text { /min }\end{array}$ & $\begin{array}{c}\text { Separation } \\
\text { rate/\% }\end{array}$ & \multicolumn{3}{c}{$\begin{array}{c}\text { Compressive } \\
\text { strength /MPa }\end{array}$} \\
\hline CAM1 & 1.4 & 19 & 95 & 0.8 & 0.16 & 0.92 & 2.6 \\
CAM2 & 1.5 & 19 & 95 & 0.8 & 0.13 & 0.87 & 2.3 \\
CAM3 & 1.6 & 19.5 & 85 & 0.7 & 0.13 & 0.85 & 2.1 \\
CAM4 & 1.7 & 20 & 75 & 0.6 & 0.11 & 0.82 & 1.9 \\
CAM5 & 1.8 & 20 & 70 & 0.6 & 0.09 & 0.80 & 1.7 \\
\hline
\end{tabular}

Table 11. Influence of A/C ratio on the properties of CAM

As can be seen from Table11, the separation rate decreased with the increase of $\mathrm{A} / \mathrm{C}$ ratio also did the fluidity and compressive strength. The proper ratio of $\mathrm{A} / \mathrm{C}$ was $0.8 \sim 1.7$ and it would be better when the ratio was around 1.6.

\section{Preparation of asphalt emulsion for CAM}

\subsection{Introduction of asphalt emulsion for CAM}

An Asphalt emulsion is asphalt dispersed through water and chemically stabilized for the emulsifier, whose preparation process is shown in Fig 15. There are two main types of emulsions with different affinity for aggregates, cationic and anionic, based on salts of fatty 
long chain molecules. Asphalt emulsions are used in cold processes for road construction and maintenance and have a wide variety of applications.Asphalt emulsion is an important part of CA mortar which possesses $10-30 \%$ of the CA mortar and its properties have greatly influenced the quality of CA mortar (FZ Wang 2009, 2010; JQ Zuo, 2005)

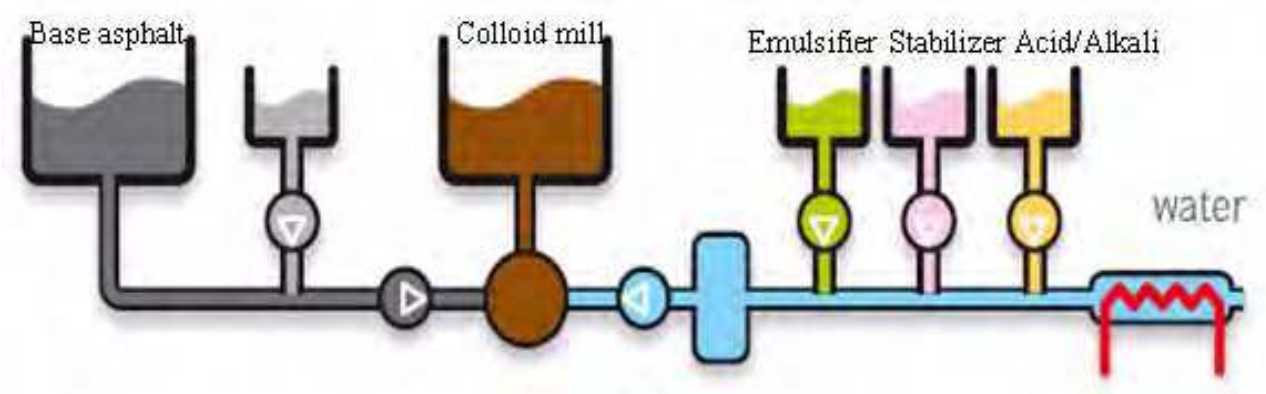

Fig. 15. Preparation process of asphalt emulsion

As shown in Table 1, the asphalt emulsion is different for different CAM and slab structure. As for I-CAM, the asphalt emulsion is cationic to make a tight combination between asphalt and inorganic material because the charges of sand when absorbing water and cement grains during hydration are both negative. However, the asphalt emulsion for II-CAM is anionic to ensure the nice cement compatibility because of the large cement content of II-CAM.

Compared to the asphalt emulsion used in highway, asphalt emulsion for CA mortar needs both nice storage stability and excellent cement compatibility. The storage stability is quite important to guarantee the properties of emulsion after long-term storage and long-distance transportation. On the other hand, the $\mathrm{C} / \mathrm{A}$ (mass ratio of cement and asphalt emulsion) of CAM is quite high $(C / A=0.60 \sim 2.04)$, this is quite different from the situation when asphalt emulsion is used just as modifier in cement mortar (Pouliot N,2003; G Li 1998; H Song 2006). The asphalt emulsion needs a good cement compatibility (or chemical stability) to keep stable when mixed with so much cement to avoid breaking thus to guarantee the workable time of CA mortar. Generally speaking, asphalt emulsion for CA mortar should have the following characteristics.

\subsubsection{Nice cement compatibility}

In the fresh cement-asphalt emulsion paste, the cement grains and asphalt droplets are dispersed isolately. The hydrophilic group of emulsifiers is directed in the aqueous phase and cement grains are intrinsically hydrophilic, also the particle sizes of cement are about 10 times as large as asphalt droplets, all of which facilitate the adsorption of asphalt droplets to cement grains. Moreover, the cement hydration consumes free water in emulsified asphalt, the spaces between the micelles in the emulsified asphalt are reduced, the electrical attraction and probability of collision between micelles increases (Song H, 2006); the $\mathrm{Ca}^{2+}$, $\mathrm{Al}^{3+}$ induced by cement hydration will also influence the double electrical layer and asphalt emulsion stability(Kulmyrzaev A,2000). Thus, asphalt emulsion needs quite nice cement compatibility to guarantee the workable properties of CAM. 


\subsubsection{Good storage stability}

Asphalt emulsion is a thermodynamically unstable system with asphalt droplets uniformly dispersed in a liquid of water and various surfactants. The droplets tend to coalescence together to decrease the surface areas and make the emulsion more stable (Ivanova R, 1999; Al-Sabagh AM 2002, Bury .M.1995). Besides that, the droplets tend to sediment due to the gravitational forces (A.S. Dukhin SSD, P.J. Goetz, 2007). So, its storage stability plays an important role in guaranteeing long-term storage and long-distance transportation (FZ Wang 2012; Ivanov IB, 1997; Ostberg GB, 1994), which is crucial in the preparation of CA mortar.

\subsubsection{Low temperature sensitivity}

When used in CAM, asphalt emulsion would finally breaking and work as the base asphalt. However, the asphalt has a high temperature sensitivity which softens at high temperature and brittles at low temperature due to its molecular structure. The climate in China is varied in different regions and the construction of high-speed railway often covers several different districts, which proposes tough requests for the temperature sensitivity of asphalt used in CAM.

\subsubsection{Environment-friendly}

As mentioned before, asphalt emulsion is the key component of CAM. But quite few emulsifiers used in asphalt emulsion are biodegradable which is harmful to the environment. Thus, the asphalt emulsion used for CAM and high-speed railway should be environment-friendly to reduce pollutions.

\subsection{Technical methods to prepare the asphalt emulsion with high performance for CAM}

To meet the requirements of asphalt emulsion for CA mortar, the technical methods were proposed as shown in Fig16, according to colloid chemistry, surface and interfacial chemistry and preparation techniques. This part would like to introduce these technique methods, respectively.

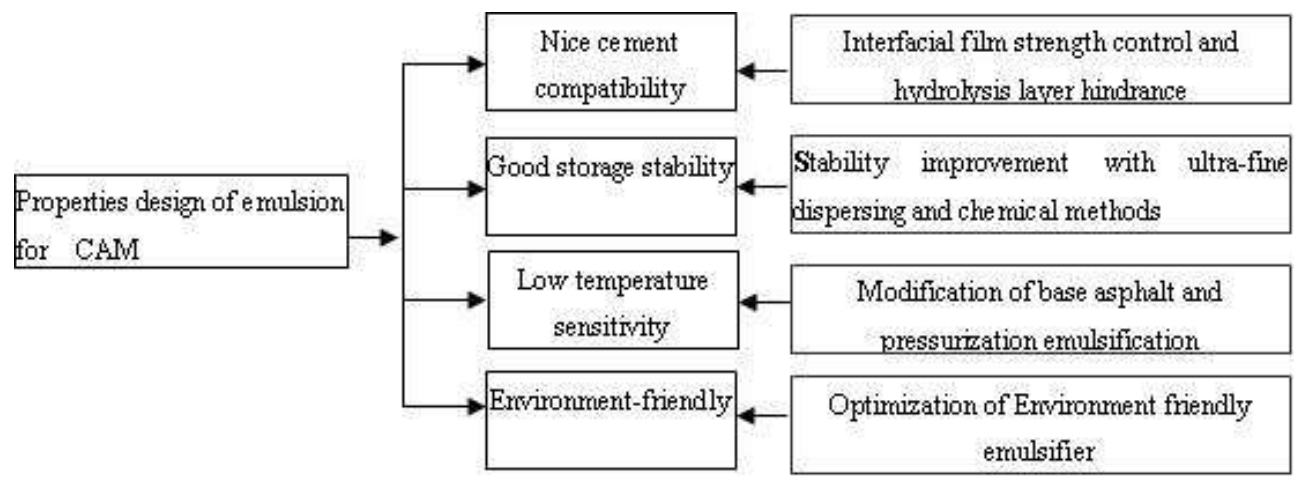

Fig. 16. Technical methods to prepare the asphalt emulsion for CAM 


\subsection{Interfacial film strength control and hydrolysis layer hindrance}

Interfacial film is the hydrolysis shell formed by the emulsifier, ionic and counter-ionic around the asphalt droplets. The tight interfacial film structure and high film strength are the key factors for emulsion stability. However, the film strength needs to be well controlled in the cement-asphalt emulsion system. When the cement absorbs the asphalt droplet or the droplets tend to coalescence, the interfacial film should have enough strength to provide hindrance to guarantee the workability of CA mortar; on the other hand, the interfacial film strength couldn't be too strong which would retard the cement hydration and influence the early strength development of CA mortar. Moreover, the temperature has a significant accelerate effect on cement hydration and droplets coalescence, the film strength needs to be controlled and adjusted according to the temperature. Thus the methods to control the interfacial film strength (FZ Wang, 2012) and hydration layer hindrance were proposed.

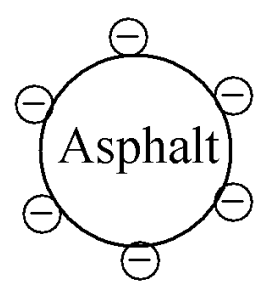

(a)

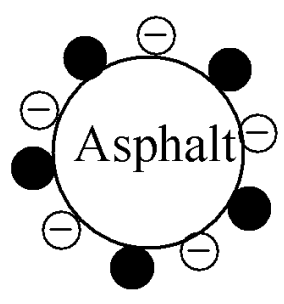

(b)

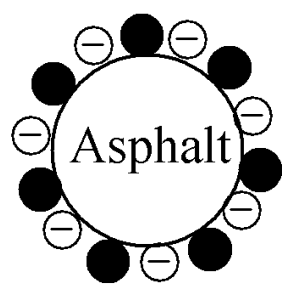

(c)

\section{$\ominus$ sodium ligninsulfonate \\ - alkylphenols polyoxyethylene}

Fig. 17. Simulation of interfacial film

Fig17 showed the simulation structure of interfacial film in anionic asphalt emulsion. As shown in Fig17-(a), the emulsifier had a loose distribution around the droplets due to the electrostatic repulsion caused by the same charges of hydrophilic molecular, so the cationic ionic induced by cement hydration were easy to damage the thin and weak interfacial film and double electric layer of droplets thus lead to emulsion breaking.

However, as for cationic asphalt emulsion, the hydrophilic molecular is mainly quaternary ammonium, of which, $\mathrm{N}$ atom has a strong adsorb ability and affinity to both cement grains and aggregates, When mixed with cements and aggregates, the droplets would soon absorb to the surface of aggregates and cement grains thus make the emulsion break soon.

The nonionic is free of charges, so it is little affected by the salts in the solution and can act like a protective colloid around the main emulsifier layer at the asphalt oil-water interface to increase the interfacial film strength and prevent the coalescence of oil droplets thus improve the emulsion stability (Gullapalli RP, Sheth BB, 1996). On the other hand, the length of nonionic emulsifier molecular is varied which provides different steric hindrance. The interfacial film can be well controlled by the optimization of nonionic emulsifiers. 
The interfacial film structures controlled by this technique can be simulated as Fig17-(b) and Fig17-(c). The composite emulsifiers were combined by the cationic emulsifiers or anionic emulsifiers with the nonionic-emulsifiers and inorganic salts. The emulsions prepared with the composite emulsifiers can be applied in the CAM constructions under different temperatures. The workable properties and early strength of CA mortar were both considered. The compatibility results with cement were shown in Table12 and Table13.

\begin{tabular}{lc}
\hline Emulsifier & Cement compatibility results \\
\hline A1 & $40^{\circ} \mathrm{C}$,stable for $4 \mathrm{~h}, 78 \mathrm{ml}$ flow out in $20 \mathrm{~s}$ \\
A2 & $40^{\circ} \mathrm{C}$,stable for $4 \mathrm{~h}, 92 \mathrm{ml}$ flow out in $20 \mathrm{~s}$ \\
D301 & $40^{\circ} \mathrm{C}$,stable for $4 \mathrm{~h}, 238 \mathrm{ml}$ flow out in $9 \mathrm{~s}$ \\
D301-H & $50^{\circ} \mathrm{C}$,stable for $4 \mathrm{~h}, 238 \mathrm{ml}$ flow out in $10 \mathrm{~s}$ \\
\hline
\end{tabular}

Table 12. Preparation of anionic composite emulsifiers

\begin{tabular}{lc}
\hline Emulsifier & Results \\
\hline C1 & Breaking after mix \\
C2 & $25^{\circ} \mathrm{C}$, sieve residue $1.9 \%$ \\
R201 & $25^{\circ} \mathrm{C}$, sieve residue $0.4 \%$ \\
R204 & $50^{\circ} \mathrm{C}$, sieve residue $0.8 \%$ \\
\hline
\end{tabular}

Table 13. Preparation of cationic composite emulsifiers

Figures 18 and 19 showed the viscosity variation of cement-asphalt emulsion paste to indicate the interaction between cement and emulsion (YP Liu, FZ Wang, 2011). Compared to the ordinary emulsion ASS-1, the ASS-2 prepared by the interfacial film strength control technique had nice compatibility with cement under $25^{\circ} \mathrm{C}, 45^{\circ} \mathrm{C}$.

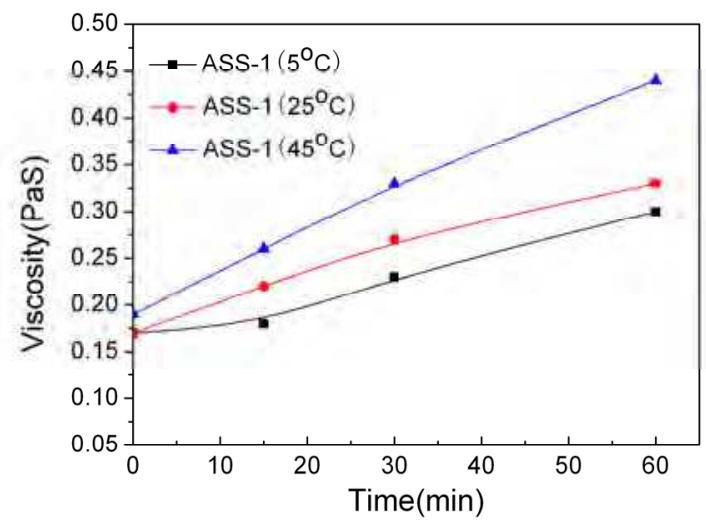

Fig. 18. Viscosity variations of CAE-1 system (ASS-1 used) 


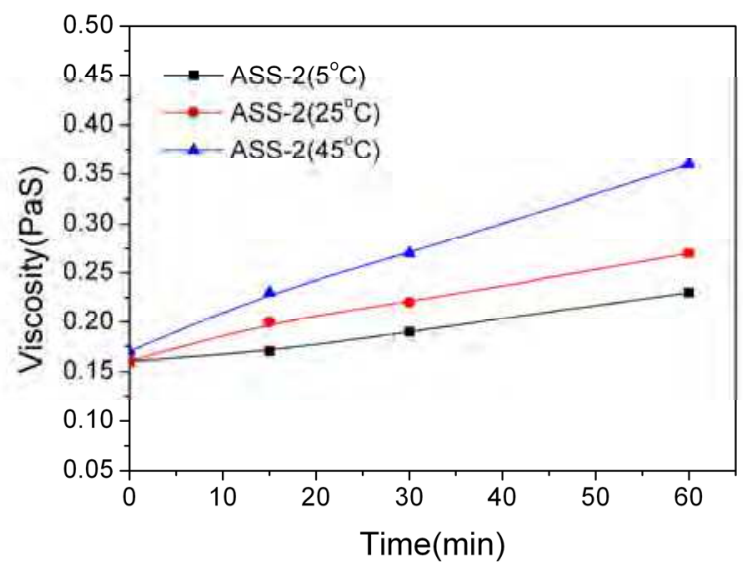

Fig. 19. Viscosity variation of CAE-2 system (ASS-2 used)

Figures20 and 21 showed the IR spectrum of R301 and R301-H in Table 12, respectively. Figures22 and 23 showed the IR spectrum of R201 and R204 in Table 13, respectively. The practical IR spectrums were almost the same with the theoretic results, which indicated that there were no chemical reactions when the main emulsifier mixed with the nonionic emulsifier. The improvement of emulsion's cement compatibility could be attributed to the addition of nonionic emulsifier. This was mainly because the nonionic emulsifier used had a larger EO numbers (EO number $=40$ ), water was easy to be absorbed to the ether group due to the hydrogen bond. One ether group usually absorbs $20 \sim 30 \mathrm{H}_{2} \mathrm{O}$ molecular. Thus a big hydrolysis layer was formed around the asphalt droplets which prevented the influences of cement hydration on emulsion breaking and improved the emulsion stability. So both the increase of interfacial film strength and thick hydrolysis layer could contribute to the improvement of emulsion's cement compatibility.

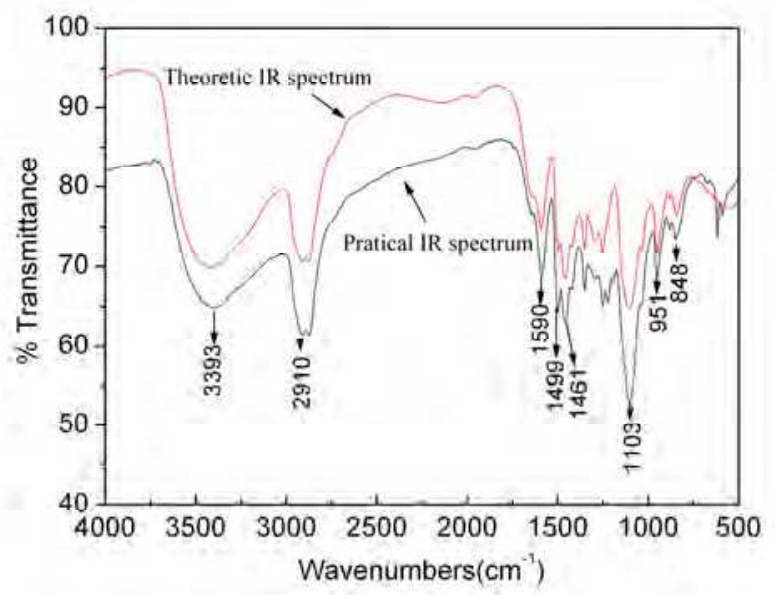

Fig. 20. Theoretic and practical IR spectrums of D301 


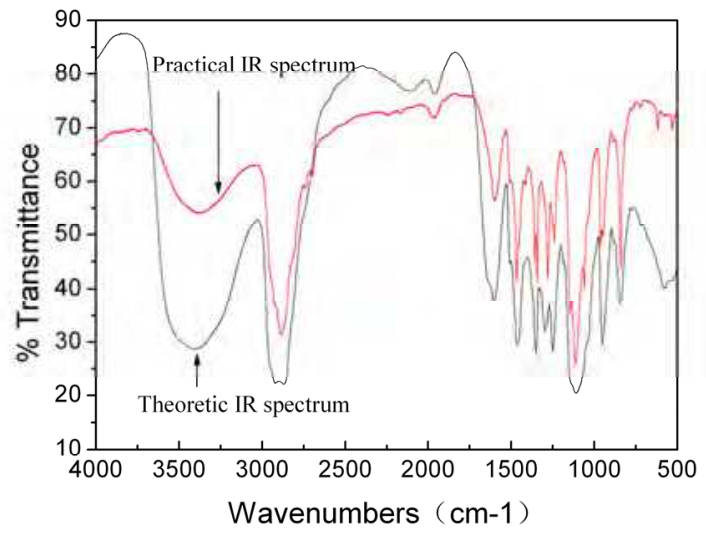

Fig. 21. Theoretic and practical IR spectrums of D301-H

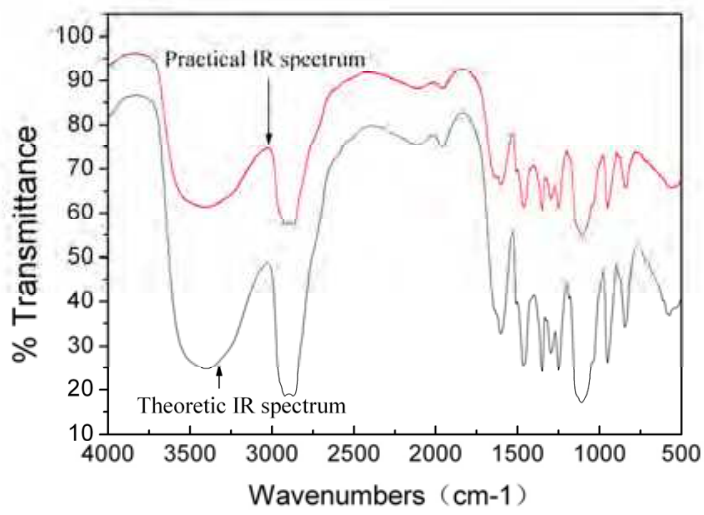

Fig. 22. Theoretic and practical IR spectrums of R201

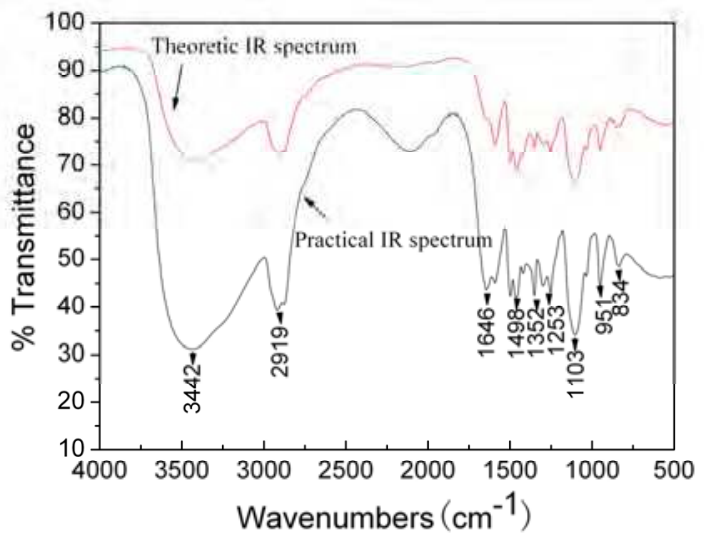

Fig. 23. Theoretic and practical IR spectrums of R204 
Figure 24 and Table 13 showed the influences of different emulsifier's solution on the early cement hydration. As can be seen, the cement hydration rate was retarded when mixed with emulsifier solution compared to the cement only mixed with water. The heat flow peak of the cement mixed with water happened after 8.8 hours; however, the time of heat flow peaks of D4 and C1 were 13.2 and 14.6 hours. This was mainly because the nonionic emulsifier and lignin-amine absorbed to the cement grains and retarded the cement hydration for steric hindrance. The $1 \mathrm{~d}$ heat of cement mixed with water was higher than that of cement with emulsifier solution, but the results after 3 days were on the contrast.

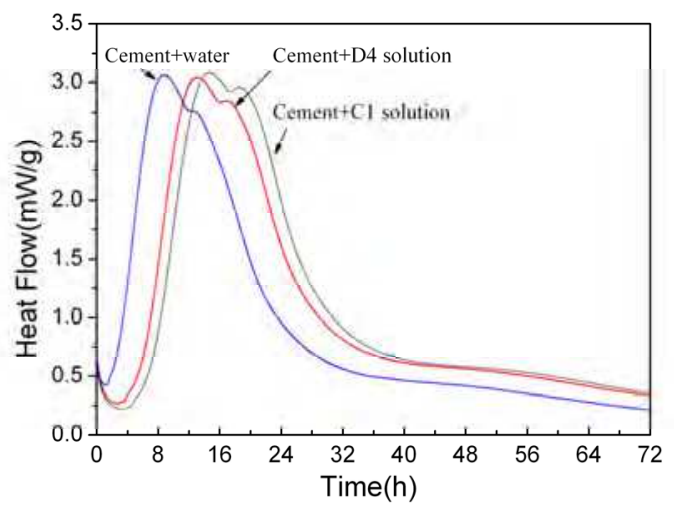

(a) Effect of emulsifier solution on heat flow of cement hydration

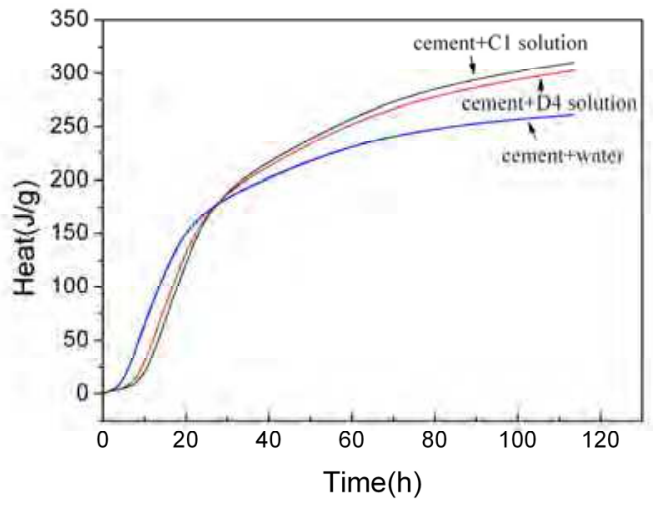

(b) Effect of emulsifier solution on heat of cement hydration

Fig. 24. Effect of emulsifier solution on cement hydration

\begin{tabular}{cccc}
\hline & Cement with water & $\begin{array}{c}\text { Cement with C1 } \\
\text { solution }\end{array}$ & $\begin{array}{c}\text { Cement with D4 } \\
\text { solution }\end{array}$ \\
\hline Peak $(\mathrm{mW} / \mathrm{g})$ & 3.06 & 3.08 & 3.04 \\
Time of Peak(h) & 8.8 & 14.6 & 13.2 \\
3days heat $(\mathrm{J} / \mathrm{g})$ & 241.1 & 274.1 & 267.6 \\
\hline
\end{tabular}

Table 13. Influence of emulsifier solution on cement hydration 


\subsection{Stability improvement with ultra-fine dispersing and chemical methods}

The asphalt emulsion was stabled by the double electric layer induced by the emulsifier. The stability is easy to be damaged when under storage and transportation. The droplets tend to sediment and coalescence together especially under stress condition. The emulsion stability mostly can be explained by the Stoke's law.

According to Stoke's law (Equation 2), the resulting sedimentation rate $v_{0}$ of a single droplet is proportional to the particle size:

$$
v_{0}=\frac{2 r^{2}\left(\rho-\rho^{\prime}\right)}{9 \eta} g
$$

Where $r$ is the hydrodynamic radius of the droplet, $\rho$ is the density of the external phase, $\rho^{\prime}$ is the density of the internal phase, $\eta$ is the macroscopic shear viscosity of the external phase, and $g$ is the gravitation constant.

In order to improve the emulsion stability, the particle sizes need to be decreased to slow down the sedimentation rate and the thickeners are used to increase the viscosity to improve the emulsion stability.

Fig25 showed the effects of particle sizes on the storage stability. As can be seen, the smaller particles lead to a stable emulsion. The smaller the particles were, the slower the sediment rate was and the emulsions were more stable. But when the particle was less than $3 \mu \mathrm{m}$, the stability was not obviously changed.

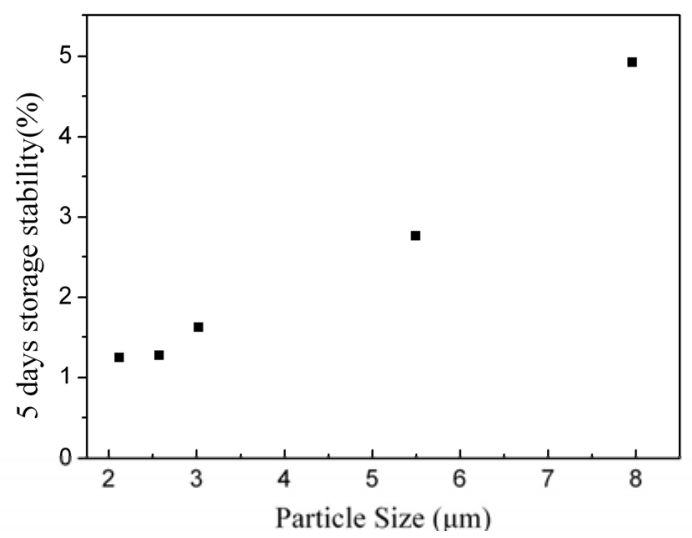

Fig. 25. Effect of particle sizes on emulsion stability

The relation between emulsification process (flow rate, flow velocity and temperatures of asphalt and emulsifier solution) and particle size was studied to develop the ultra-fine dispersing technique. The results were shown in Fig26, and as can be seen, the particle sizes of droplets were greatly reduced. The composite stabilizers combined with thickeners, inorganic salts and nonionic emulsifiers were prepared to improve the emulsion stability. As shown in Fig27, the emulsion stability was significantly improved, even under higher temperature (FZ Wang, 2012). 


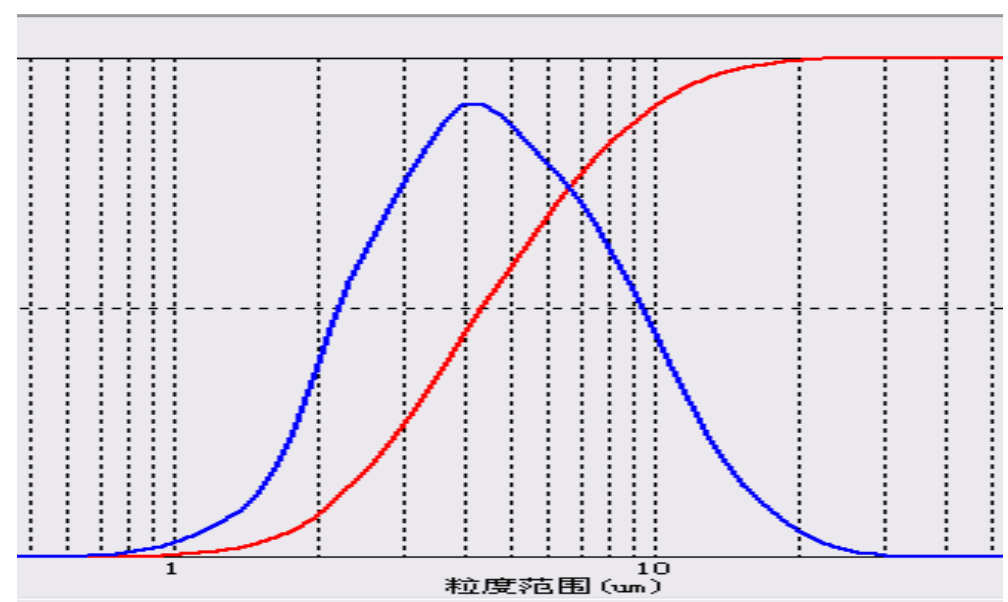

(a) Common technique (Average particle size $4.99 \mu \mathrm{m}$ )

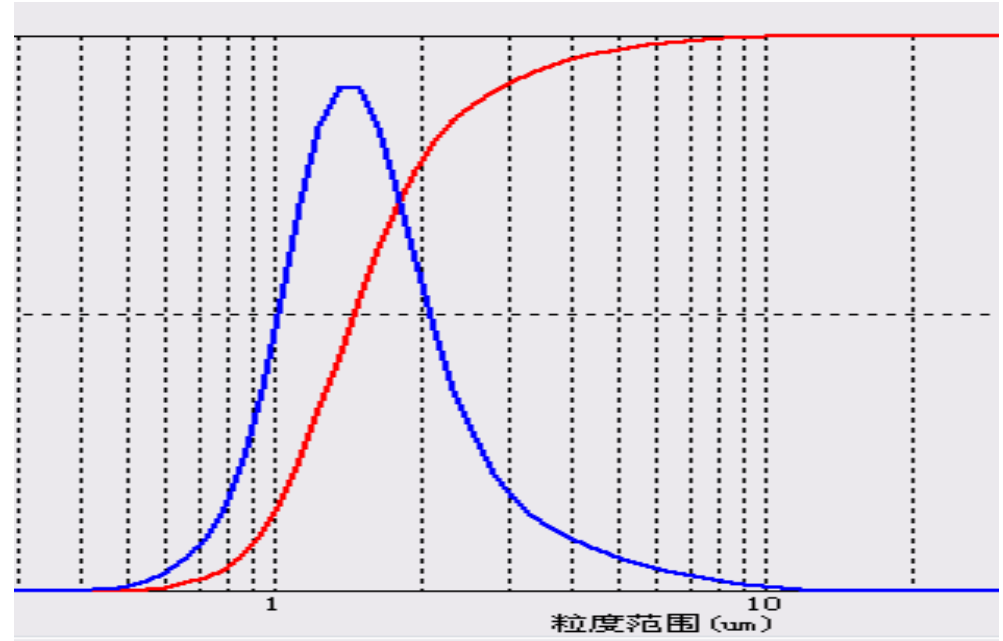

(b) Ultrafine dispersing technique (Average particle size $1.37 \mu \mathrm{m}$ )

Fig. 26. Effect of the ultrafine dispersing technique on particle size of asphalt emulsion 


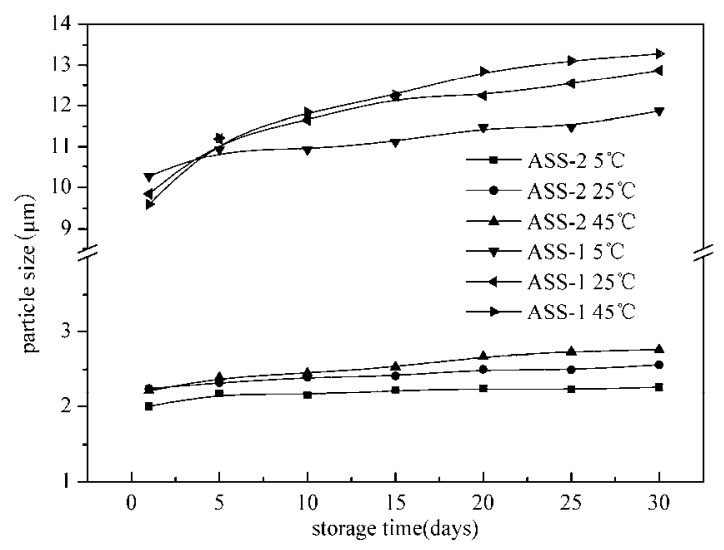

(a) Particle size variations

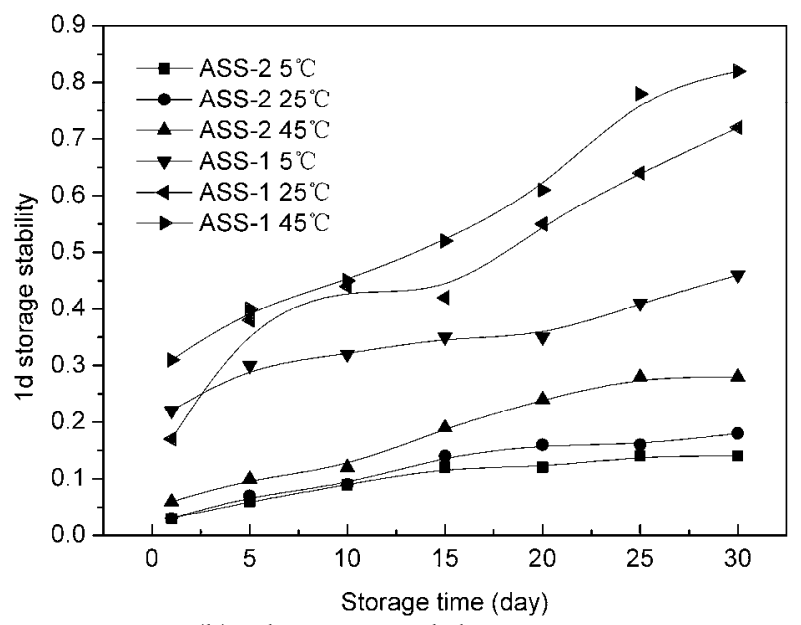

(b) 1d storage stability variations

Fig. 27. Emulsion storage stability variations under different temperatures

Table14 showed the influences of different types thickeners including polyvinyl alcohol (PVA), corn starch (CS), cellulose ether with low molecular weight (K1), cellulose ether with large molecular weight (K4) on the storage stability and Engler viscosity.

\begin{tabular}{lcc}
\hline Thickeners type & 1d Storage stability $(\%)$ & Engler viscosity $\left(25^{\circ} \mathrm{C}\right)$ \\
\hline- & 13.6 & 4.17 \\
$\operatorname{PVA}(0.03 \%)$ & 8.0 & 4.43 \\
$\mathrm{C} S(0.03 \%)$ & 0.3 & 10.36 \\
$\mathrm{~K} 1(0.03 \%)$ & 2.4 & 8.2 \\
$\mathrm{~K} 4(0.03 \%)$ & 4.1 & 6.9 \\
\hline
\end{tabular}

Table 14. Influence of thickeners on the emulsion stability 
As can be seen from Table 14, the thickeners significantly increased the Engler viscosity of emulsion, even with the dosage $0.03 \%$. Of which, the corn starch played the best thickening effects with the Engler viscosity 10.36 and the best emulsion storage stability $0.3 \%$. The effects of PVA were not obvious with the dosage $0.03 \%$ for the Engler viscosity was slightly increased.

Fig28 showed the influences of K4 dosages on the Engler viscosity and emulsion stability. As can be seen, the Engler viscosity was opposite with the storage stability. The Engler viscosity increased and the emulsion stability decreased with the increase of $\mathrm{K} 4$ dosage, which indicated the emulsion more stable. The emulsion stability had a slight change when the K4 dosage was over $0.06 \%$.

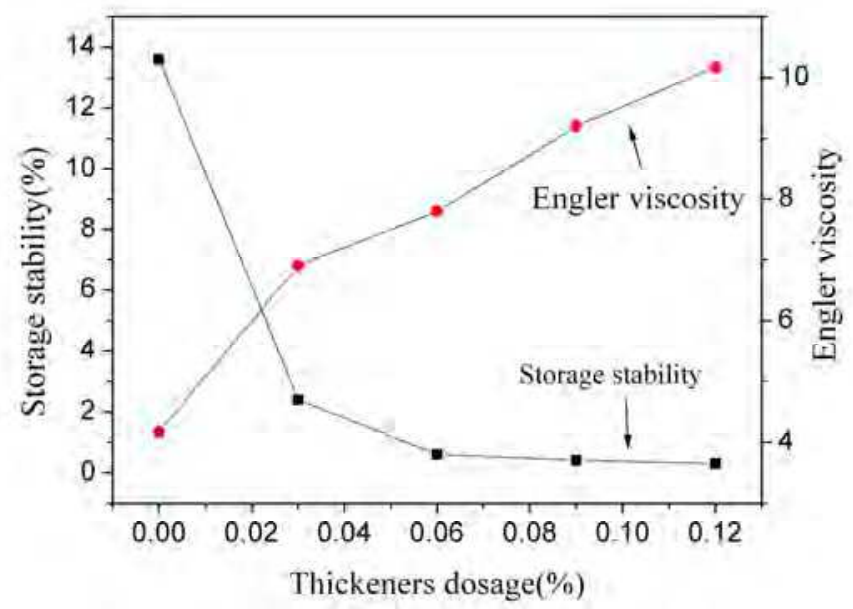

Fig. 28. Effect of thickeners dosage on emulsion stability

\subsection{Modification of base asphalt and pressurization emulsification}

The base asphalt used for asphalt emulsion are usually 90\# -70\# heavy traffic paving asphalt without modification. However, the asphalt emulsion evaporation residue prepared with these asphalt had a smaller softening point and low temperature ductility which can't stand the complicated climate, especially in China. To improve the temperature sensitivity of emulsion, styrene-bu-tadiene block copolymer (SBS), styrenebutadiene rubbers (SBR) are often added into the asphalt emulsion to prepare modified asphalt emulsion. However, emulsions prepared with the "first emulsification, then modification" method is usually not homogeneity because it's hard to form crosslink structure between asphalt and modifier. The softening point of the emulsion evaporation residue is hard to over $70^{\circ} \mathrm{C}$ and the $5^{\circ} \mathrm{C}$ ductility is less than $20 \mathrm{~cm}$, which could not meet the requirements of hot and cold regions.

There is also another modification method namely "first modification, then emulsification" method. This technique is to modify the base asphalt with SBS first and then prepare the emulsion. The temperature sensitivity is improved with the increase of SBS dosages, but the emulsification is more difficult at the same time. 
When prepared the asphalt emulsion, the base asphalt modified with SBS usually need to be heated to be over $170^{\circ} \mathrm{C}$, but the temperature of emulsifier solution is usually $50 \sim 60^{\circ} \mathrm{C}$, which make the temperature difference between these two parts over $100^{\circ} \mathrm{C}$, thus induce serious water gasification.

To solve this problem, the pressurization emulsification method was proposed combined with high shearing speed and pressurization in emulsion system to prevent the water gasification and guarantee the emulsification process.

Table15 showed the different emulsification process parameters for modified asphalt with different SBS dosages. As can be seen, both the colloid mill speed and the emulsification system pressure increased with the increase of SBS dosage.

\begin{tabular}{lccc}
\hline \multirow{2}{*}{ Number } & SBS dosages (\%) & \multicolumn{2}{c}{ Emulsification process parameter } \\
\cline { 3 - 4 } & & $\begin{array}{c}\text { Sheer speed of colloid mill } \\
/ \mathrm{r} / \mathrm{min}\end{array}$ & $\begin{array}{c}\text { Emulsification system } \\
\text { pressure/MPa }\end{array}$ \\
\hline 1 & 3 & 9000 & 0.3 \\
2 & 4 & 10000 & 0.4 \\
3 & 5 & 11000 & 0.6 \\
\hline
\end{tabular}

Table 15. Emulsification process parameter of asphalt modified with different SBS dosages

Table16 showed the properties of modified emulsion's evaporation residue with different SBS dosages. As can be seen, the temperature sensitivity was improved with the increase of SBS dosage. When the SBS dosage was over 3\%, SBS formed an interpenetrating structure through the asphalt. The formation of net structure increased the viscosity and elasticity of modified asphalt thus increased the softening point.

\begin{tabular}{lccc}
\hline \multirow{2}{*}{ Number } & \multirow{2}{*}{ SBS dosage $(\%)$} & \multicolumn{2}{c}{ Properties of emulsion evaporation residue } \\
\cline { 3 - 4 } & 0 & Softening point $/{ }^{\circ} \mathrm{C}$ & Ductility $/ 5^{\circ} \mathrm{C}, \mathrm{cm}$ \\
\hline 1 & 3 & 68 & $/$ \\
2 & 4 & 75 & 20 \\
3 & 5 & 81 & 22 \\
4 & & 75 & 26 \\
\hline
\end{tabular}

Table 16. Properties of resin asphalt modified with different SBS dosage

Considering the costs and emulsion stability prepared with modified asphalt with higher SBS dosage, the properties of asphalt emulsion modified both with SBS and SBR latex were studied. The base asphalt was first modified with SBS and then the emulsion was prepared, after this, SBR latex was used to modify the emulsion. Table 17 showed that $5^{\circ} \mathrm{C}$ ductility was greatly improved with this method, and the softening point also reached $64^{\circ} \mathrm{C}$ which indicated the asphalt emulsion also had low temperature sensitivity.

\begin{tabular}{lccc}
\hline \multirow{2}{*}{ Number } & $\begin{array}{c}\text { Modification } \\
\text { Method }\end{array}$ & \multicolumn{2}{c}{ Properties of emulsion evaporation residue } \\
\cline { 3 - 4 } & $/$ & Softening point $/{ }^{\circ} \mathrm{C}$ & Ductility $/ 5^{\circ} \mathrm{C}, \mathrm{cm}$ \\
\hline 1 & $3 \% \mathrm{SBS}+2 \% \mathrm{SBR}$ & 68 & $/$ \\
2 & 64 & 52 \\
\hline
\end{tabular}

Table 17. Properties of asphalt emulsion prepared with different modification methods 


\subsection{Properties of asphalt emulsion}

The asphalt emulsion with excellent cement compatibility, nice storage stability and low temperature sensitivity was prepared with the technology mentioned before which included interfacial film strength control and hydrolysis layer hindrance, stability improvement with ultra-fine dispersing and chemical methods, modification of base asphalt and pressurization emulsification. The properties of cationic emulsion and anionic emulsion were listed in Tables18 and 19, respectively.

\begin{tabular}{|c|c|c|c|c|c|c|}
\hline Number & Technical index & Unit & $\begin{array}{c}\text { Standard } \\
\text { requirements }\end{array}$ & CAE-1 & CAE-2 & CAE-3 \\
\hline 1 & Particle charge & / & Cationic & Cationic & Cationic & Cationic \\
\hline 2 & Engler viscosity $\left(25^{\circ} \mathrm{C}\right)$ & / & $5 \sim 15$ & 9 & 10 & 9 \\
\hline 3 & Sieve tests $(1.18 \mathrm{~mm})$ & $\%$ & $<0.1$ & 0 & 0 & 0 \\
\hline 4 & $\begin{array}{l}\text { Storage stability } \\
\quad\left(1 \mathrm{~d}, 25^{\circ} \mathrm{C}\right)\end{array}$ & $\%$ & $<1.0$ & 0.6 & 0.3 & 0.1 \\
\hline 5 & $\begin{array}{l}\text { Storage stability } \\
\qquad\left(5 \mathrm{~d}, 25^{\circ} \mathrm{C}\right)\end{array}$ & $\%$ & $<5.0$ & 2.2 & 1.6 & 1.2 \\
\hline 6 & Storage stability $\left(-5^{\circ} \mathrm{C}\right)$ & / & $\begin{array}{l}\text { No coarse } \\
\text { grains }\end{array}$ & Qualified & Qualified & Qualified \\
\hline 7 & Cement compatibility & $\%$ & $<1.0$ & 0 & 0 & 0 \\
\hline \multirow{4}{*}{8} & Solid contents & $\%$ & $58 \sim 63$ & 59.2 & 60.5 & 59.8 \\
\hline & $\begin{array}{c}\text { Penetration }\left(25^{\circ} \mathrm{C},\right. \\
100 \mathrm{~g})\end{array}$ & $\begin{array}{c}0.1 \mathrm{~m} \\
\mathrm{~m}\end{array}$ & $60 \sim 120$ & 64 & 51 & 74 \\
\hline & $\begin{array}{l}\text { Softening point } \\
\qquad\left({ }^{\circ} \mathrm{C}\right)\end{array}$ & ${ }^{\circ} \mathrm{C}$ & / & 70.4 & 76.5 & 48.1 \\
\hline & Ductility $\left(5^{\circ} \mathrm{C}\right)$ & $\mathrm{cm}$ & $\geq 20$ & 33.5 & 20.8 & 55.6 \\
\hline
\end{tabular}

Table 18. Properties of cationic asphalt emulsion for CA mortar 


\begin{tabular}{|c|c|c|c|c|c|c|c|}
\hline Number & & hnical index & Unit & $\begin{array}{c}\text { Standard } \\
\text { requiremen } \\
\text { ts }\end{array}$ & AAE-1 & AAE-2 & AAE-3 \\
\hline 1 & Sieve & tests $(1.18 \mathrm{~mm})$ & $\%$ & $<0.1$ & 0.03 & 0.02 & 0.05 \\
\hline 2 & & ticle charge & / & anionic & anionic & anionic & anionic \\
\hline 3 & & article size & $\mu \mathrm{m}$ & $\begin{array}{l}\text { Average } \\
\text { particle } \\
\text { size } \leq 7\end{array}$ & $\begin{array}{l}\text { Average } \\
\text { particle } \\
\text { size=2.3; }\end{array}$ & $\begin{array}{l}\text { Average } \\
\text { particle } \\
\text { size=3.8; }\end{array}$ & $\begin{array}{l}\text { Average } \\
\text { particle } \\
\text { size=1.8; }\end{array}$ \\
\hline 4 & Ceme & tt compatibility & $\mathrm{ml}$ & $\geq 70$ & 240 & 240 & 240 \\
\hline 5 & Sto & $\begin{array}{l}\text { cage stability } \\
\left(1 \mathrm{~d}, 25^{\circ} \mathrm{C}\right)\end{array}$ & $\%$ & $<1.0$ & 0.6 & 0.4 & 0.8 \\
\hline 6 & Sto & $\begin{array}{l}\text { age stability } \\
\left(5 \mathrm{~d}, 25^{\circ} \mathrm{C}\right)\end{array}$ & $\%$ & $<5.0$ & 2.4 & 2.3 & 2.4 \\
\hline 7 & Storag & stability $\left(-5^{\circ} \mathrm{C}\right)$ & / & $\begin{array}{l}\text { No coarse } \\
\text { grain }\end{array}$ & Qualified & Qualified & Qualified \\
\hline 8 & \multirow{4}{*}{ 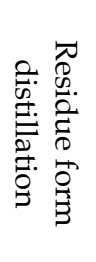 } & Solid contents & $\%$ & $\geq 60$ & 61.8 & 61.0 & 62.1 \\
\hline 9 & & $\begin{array}{l}\text { Penetration } \\
\left(25^{\circ} \mathrm{C}, 100 \mathrm{~g}\right)\end{array}$ & $0.1 \mathrm{~mm}$ & $40 \sim 120$ & 64 & 48 & 73 \\
\hline 10 & & $\begin{array}{l}\text { Softening point } \\
\left({ }^{\circ} \mathrm{C}\right)\end{array}$ & ${ }^{\circ} \mathrm{C}$ & $\geq 42$ & 70.6 & 75.8 & 46.0 \\
\hline 11 & & Ductility $\left(5^{\circ} \mathrm{C}\right)$ & $\mathrm{cm}$ & $\geq 20$ & 31.8 & 22.1 & 53.4 \\
\hline
\end{tabular}

Table 19. Properties of anionic asphalt emulsion

\section{Preparation of dry blend for CAM}

The properties design of CAM must meet the requirements of construction. The structure of slab track in high-speed railway determines the unique construction method- grouting method. CAM was directly grouted in the narrow spaces between the concrete roadbed and slab track with its gravitational force. CAM must have both nice mechanical properties and workability to adjust to this method. This part mainly introduced the main techniques that improved and controlled the rheological properties of CAM by the dry blend composition and mix proportion designs, which was also the core technology of preparation for dry blend and CAM.

\subsection{Design of rheological properties of CAM}

\subsubsection{Construction procedure of slab track}

As for CRTS I slab track, CAM would be grouted into the inject bag that was preset under the slab track. There were three types of different dimensions of slab track which were $4962 \times 2400 \mathrm{~mm}, 4856 \times 2400 \mathrm{~mm}$ and $3685 \times 2400 \mathrm{~mm}$. However, as for CRTS II slab track, the CAM would be directly grouted into the narrow space between the slab track and concrete roadbed $(6450 \times 2550 \times 30 \mathrm{~mm})$. The grouting process was influenced by the interface property between CAM and concrete because the CA mortar contacted with the roadbed and slab track directly. 


\subsubsection{Design of CAM flow state}

Fig29 showed the schematic diagrams of grouting process for CRTS I and II slab tracks. The grouting and filling processes of CAM under the slab track were accompanied with the gas exhaust process. The I CAM were injected in the filling bag that was squeezed vacuum, CAM filled the filling bag with extrusion which could prevent the bubbles to be brought in the CAM that would influence the interfacial quality between CAM and slab track. However, this was quite different for II CAM. When the II CAM were grouted, the mortar directly contacted with the roadbed concrete and slab track. The filling process indeed was the process that replacement of gas in the space by CAM. Thus, the flowability of CAM directly influenced the replacement effects.

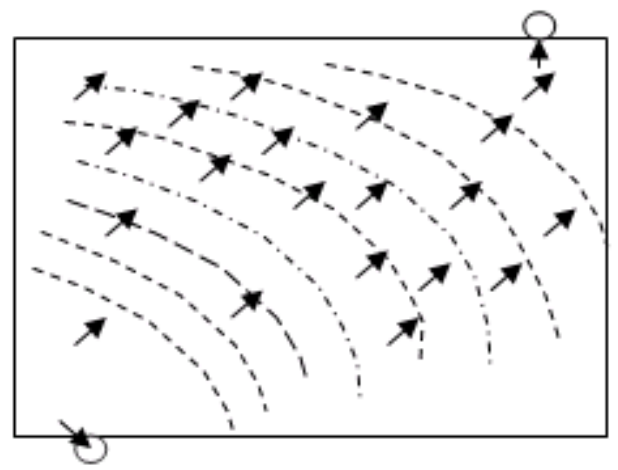

(a) CRTS I CAM

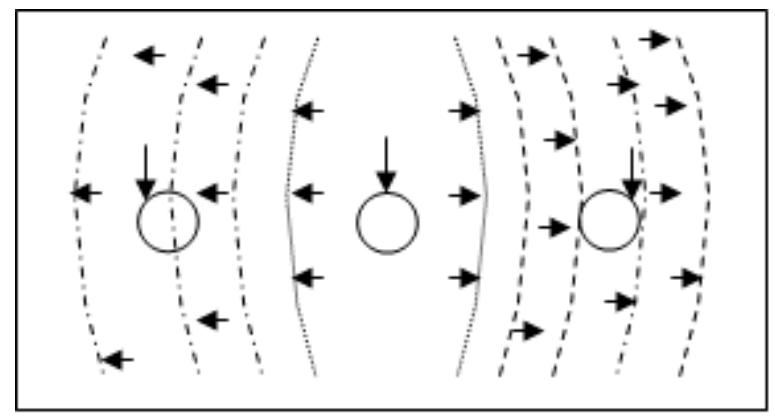

(b) CRTS-II CAM

Fig. 29. Schematic diagram of grouting process for CRTS I and II slab tracks

Thus, the rheological properties of CAM were the key factors to guarantee the filling effect of CAM under the slab track. The basic flow pattern of fluid could be divided into Newtonian fluid and non-Newtonian fluid. Newtonian fluids like water and air are the fluids with the constant viscosity. However, the Bingham model is usually to study the rheological properties of fresh concrete and cement paste. The Bingham liquid usually had a critical shear stress (or "yield stress"), once the yield stress is exceeded, the fluid began to flow. The equation is shown as 


$$
\tau=\tau_{0}+\eta_{0} \frac{d v}{d x}
$$

Where: $\tau$-shear stress $(\mathrm{Pa}) ; \tau_{0}$-yield stress $(\mathrm{Pa}) ; \eta_{0}$-viscosityPa $\left.\mathrm{S}\right) ; \mathrm{dv} / \mathrm{dx}$ - shear rate( $\left.\mathrm{S}^{-1}\right)$.

According to our study (Wang FZ, Wang T, 2008), CAM also belonged to Bingham fluid. The shear stress and shear rate followed the equation 3.

CAM needs to have both nice flowability and good homogeneity without separation, to fill the huge narrow space thoroughly with the help of rheological agents. As can be seen from the equation 3 , the yield stress $\tau_{0}$ and the viscosity $\eta_{0}$ determines the rheological properties. CAM would have an increased flow resistance with increased viscosity and a bad homogeneity with small viscosity; on the other hand, CAM needs a proper shear stress $\tau_{0}$. When the shear stress $\tau_{0}$ was too small, the rheological properties of CAM would be similar with the Newtonian fluid, which had a nice flowability but was easy to separate; when the shear stress $\tau_{0}$ was too large, it would be hard for CAM to fill the space fully because CAM would not flow unless with a larger shear rate. In short, the purpose to use the rheological agents is to coordinate the balance between the flowability and homogeneity; also to control the flow state of CAM thus to guarantee the grouting process.

\subsection{Preparation of rheological agents}

The rheological agents are usually divided into inorganic and organic agents. Fig 30 showed the influences of common inorganic rheological agents on the CAM's rheological properties and CMC were prepared to control the flow state of CAM (yield stress $\tau_{0}$ and viscosity $\eta_{0}$ ). The organic agents that were commonly used included Polyacrylamide, sodium polyacrylate, polyvinyl alcohol and cellulose ether, which mainly increased the paste viscosity. The organic rheological agents VMA were prepared which could keep the homogeneity of paste but have little effect on the flowability.

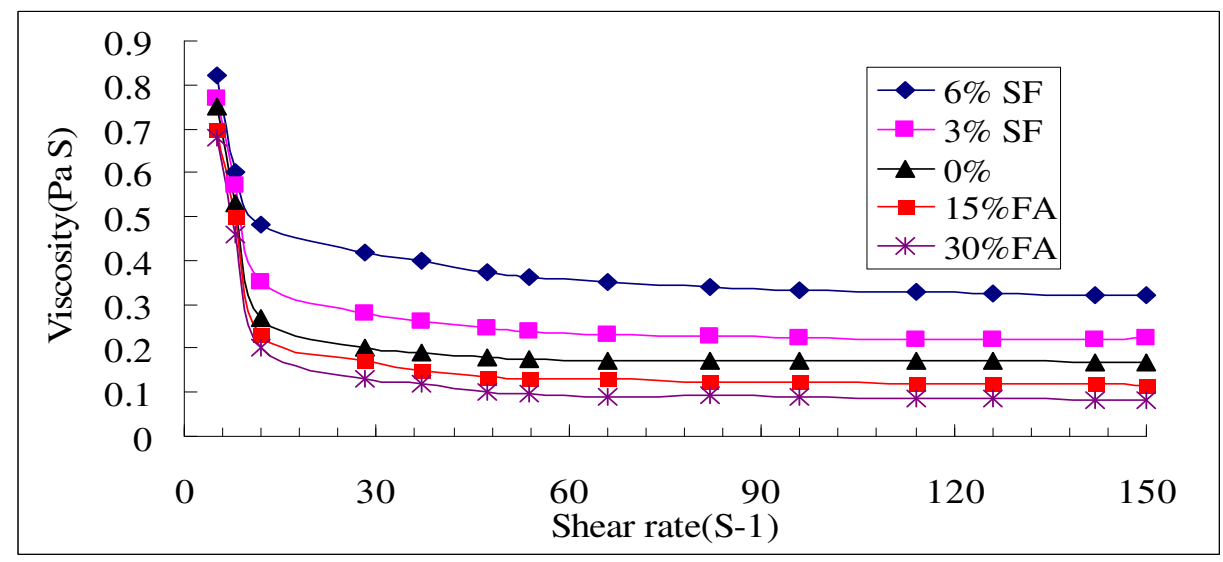

Fig. 30. Influence of inorganic rheological agents on the CAM rheological properties 
The flow state of CAM can be evaluated by indexes like flowability, spreading and spreading speed. The influences of CMC and VMA on the rheological properties of CAM were shown in Table20.

\begin{tabular}{lccccc}
\hline Number & VMA & CMC & Flowability/s & Spreading/mm & D280/s \\
\hline CAM-1 & 0 & 0 & 90 & 350 & 5 \\
CAM-2 & $\sqrt{ }$ & 0 & 118 & 340 & 6 \\
CAM-3 & $\sqrt{ }$ & $\sqrt{ }$ & 115 & 320 & 8 \\
\hline
\end{tabular}

Note: CAM here referred to II CAM

Table 20. Influence of CMC and VMA on the rheological properties of CAM

\subsection{The key technology to prepare the dry blend for CAM}

As mentioned before, the CAM for high-speed railway was usually consisted of five parts which were asphalt emulsion, dry blend, superplasticizer, anti-foaming agent and water. Of which, dry blend was consisted of cement, sand and other powder material that adjusted the CAM properties. The powder materials that adjusted the CAM properties were usually expansion agent, aluminum powder and rheological agents. The key technology to prepare the dry blend for CAM was to control the stability of raw materials, grading of sand and uniform addition of adjust materials with small amount.

\subsubsection{Dynamic controlling of sand grading}

Sand is the raw material with maximum demand for CAM preparation whose properties are hard to control. The grading and mud contents are quite important for the CAM quality. The sand grading influenced its fineness. At a constant weight, the surface area increased with the decrease of fineness, which increased the paste that coated the sand and the water to make the CAM have the same flowability. At the same time, the grading and surface morphology of sands influenced the packing tightness of aggregates and the flow state of CAM. The influences of sand fineness on the CAM properties were shown in Table 21.

\begin{tabular}{|c|c|c|c|c|c|c|c|c|}
\hline \multirow[t]{2}{*}{ Number } & \multirow[t]{2}{*}{ Sand } & \multirow{2}{*}{$\begin{array}{l}\text { Fineness } \\
\text { modulus }\end{array}$} & \multirow{2}{*}{$\begin{array}{c}\text { Flowability } \\
\text { /s }\end{array}$} & \multirow{2}{*}{$\begin{array}{l}\text { Workable } \\
\text { time/min }\end{array}$} & \multirow{2}{*}{$\begin{array}{c}\text { Separation } \\
\text { rate } / \%\end{array}$} & \multicolumn{3}{|c|}{$\begin{array}{c}\text { Compressive strength } \\
\qquad / \mathrm{MPa}\end{array}$} \\
\hline & & & & & & $1 d$ & $7 d$ & $28 d$ \\
\hline S2 & $\begin{array}{l}\text { River } \\
\text { sand }\end{array}$ & 1.4 & 20.5 & 65 & 0.6 & 0.13 & 0.83 & 2.1 \\
\hline S3 & $\begin{array}{l}\text { River } \\
\text { sand }\end{array}$ & 1.7 & 19.5 & 85 & 0.7 & 0.13 & 0.85 & 2.1 \\
\hline S4 & $\begin{array}{l}\text { River } \\
\text { sand }\end{array}$ & 2.3 & 19 & 95 & 3.1 & 0.11 & 0.75 & 1.75 \\
\hline S5 & $\begin{array}{l}\text { Silica } \\
\text { sand }\end{array}$ & 1.4 & 19.5 & 90 & 0.9 & 0.12 & 0.8 & 2.05 \\
\hline
\end{tabular}

Table 21. Influences of sand fineness on the CAM properties 
As shown in Table21, the homogeneity of CAM decreased with the increase of sand fineness modulus. The proper fineness modulus should be controlled within 1.4 1.7.

The powders with the particle sizes less than $0.15 \mathrm{~mm}$ in dry blend were cements and mineral powders. Of which, cement is the key component to guarantee the compressive strength of CAM and inert material is the component to increase the viscosity of dry blend to prevent the CAM separation. The experimental results indicated that, CAM had a nice rheological properties without separation when the contents of powders with particle sizes less than $0.15 \mathrm{~mm}$ were about $40 \sim 50 \%$; when the content was less than $40 \%$, CAM was easy to separate and bleed; when the content was larger than $50 \%$, more water was needed and the viscosity and flowability of CAM increased which made CAM hard to fill the spaces.

\subsubsection{Uniform addition of adjustment materials with small amount}

The contents of adjustment materials were quite small in the dry blend of CAM. For example, the weight of aluminum powder in the dry blend per ton was about $10 \sim 30 \mathrm{~g}$ and the weight of rheological agents were $3 \sim 8 \mathrm{~kg}$. Although the amount was quite small, the uniform distribution of these materials in dry blend was quite important for the rheological properties and durability of CAM. Thus, the uniform addition technology is quite important. So the adjustment materials were pre-mixed with carrier like sand or cement, then the sand was added by several times to make the carrier with the adjust materials dispersed more evenly.

\section{Application of CAM on Beijing-Shanghai high-speed railway}

Beijing-Shanghai high speed railway is the longest high-speed railway with the most strict quality requirements in the world. We have taken part in the railway construction by providing the CAM prepared the technology mentioned in the chapter. Fig31-41 showed the key construction process during construction of CRTS II CAM in Jing-Hu high-speed railway.

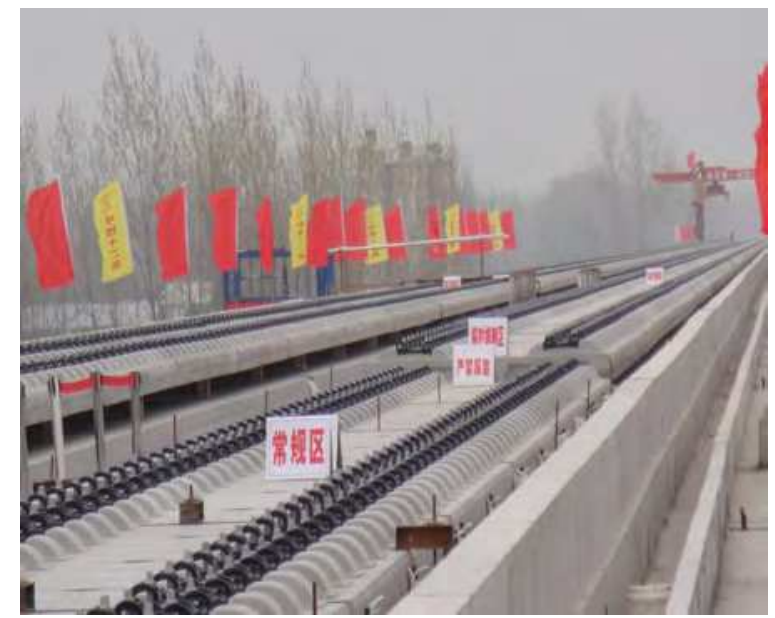

Fig. 31. Preparation before grouting 


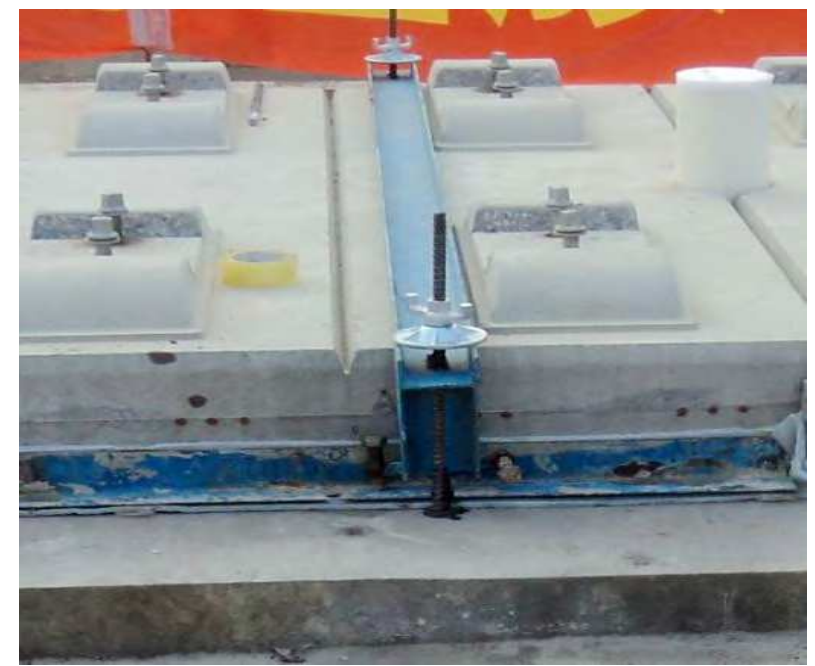

Sealing Edge (a)

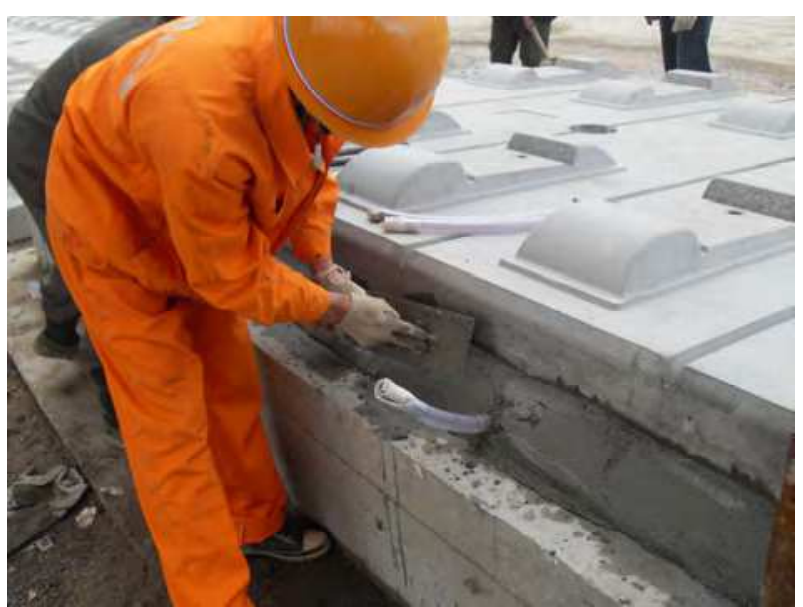

Sealing Edge (b)

Fig. 32. Sealing Edge 


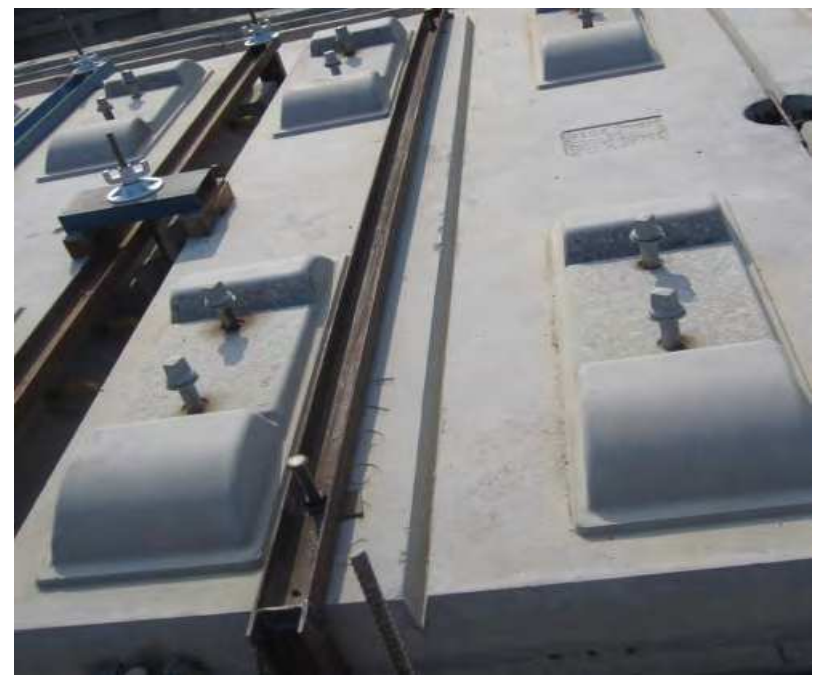

Fig. 33. Tight the slab track

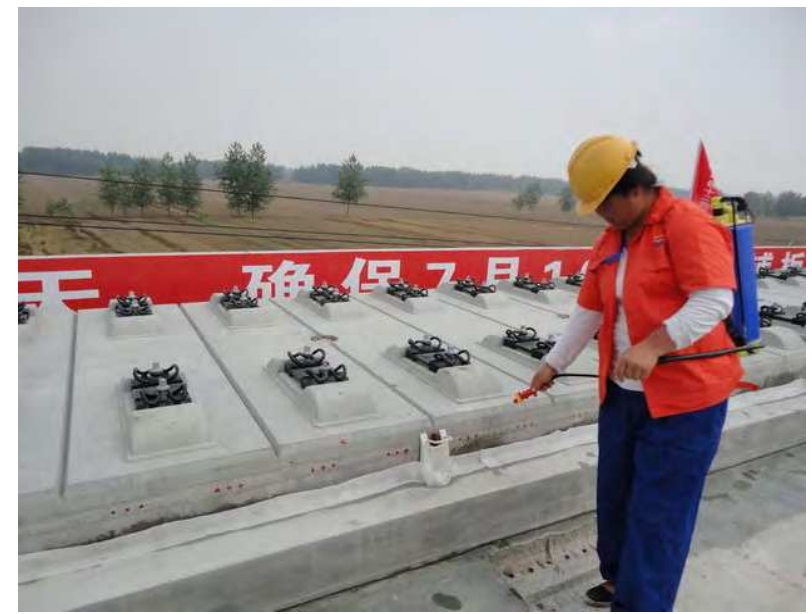

Fig. 34. Wetting 


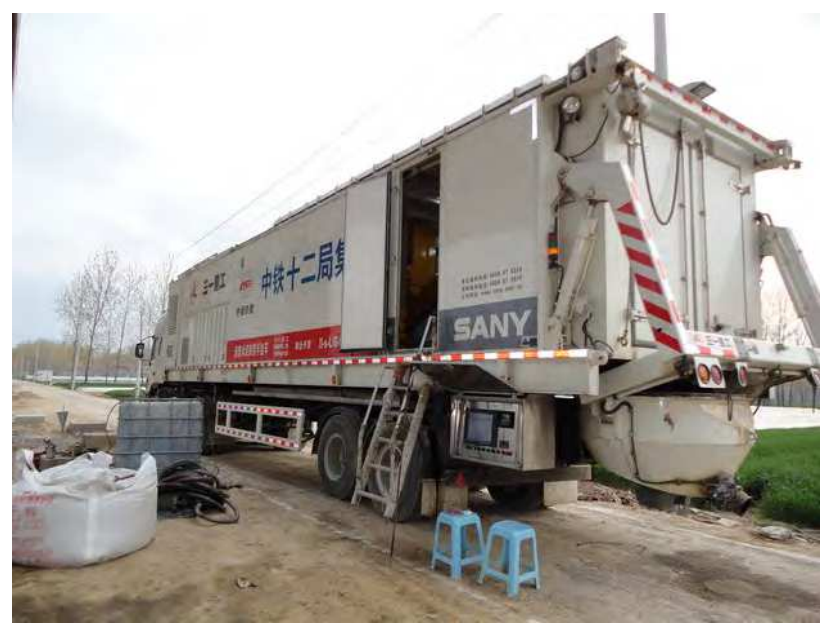

Fig. 35. Preparation of CA mortar 


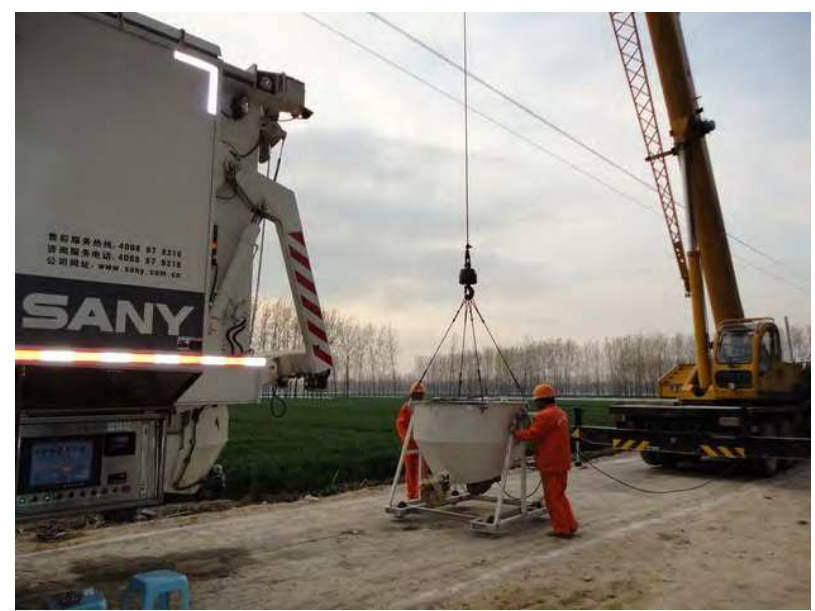

(a)Transportation of CA mortar

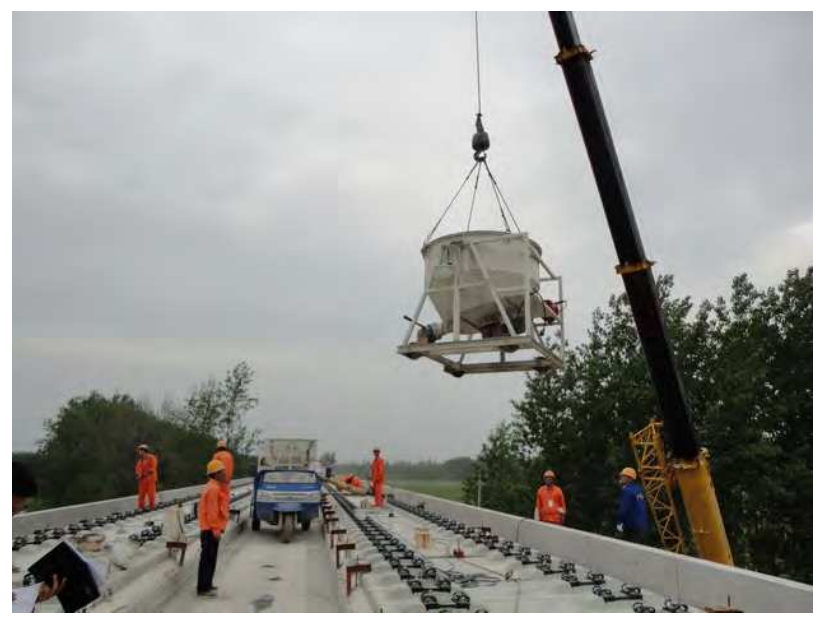

(b)Transportation of CA mortar

Fig. 36. Transportation of CA mortar 


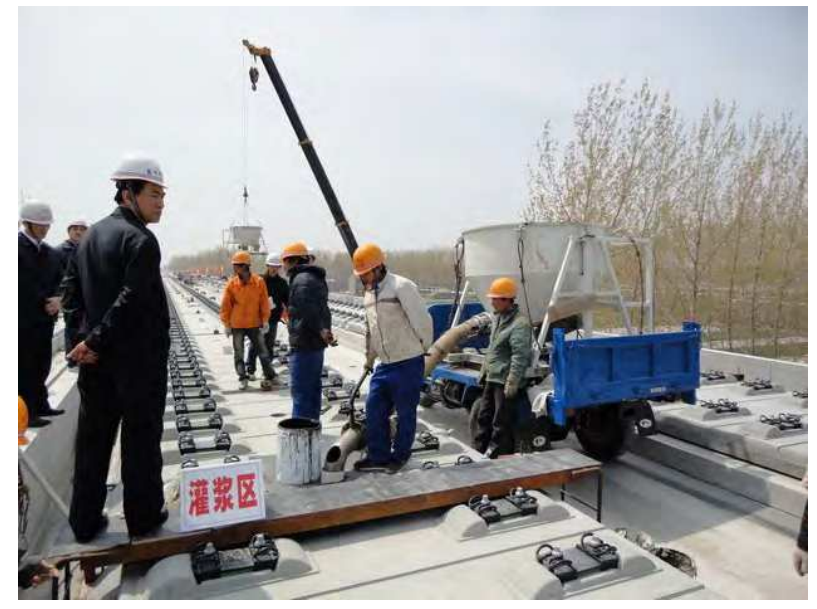

Fig. 37. Grouting

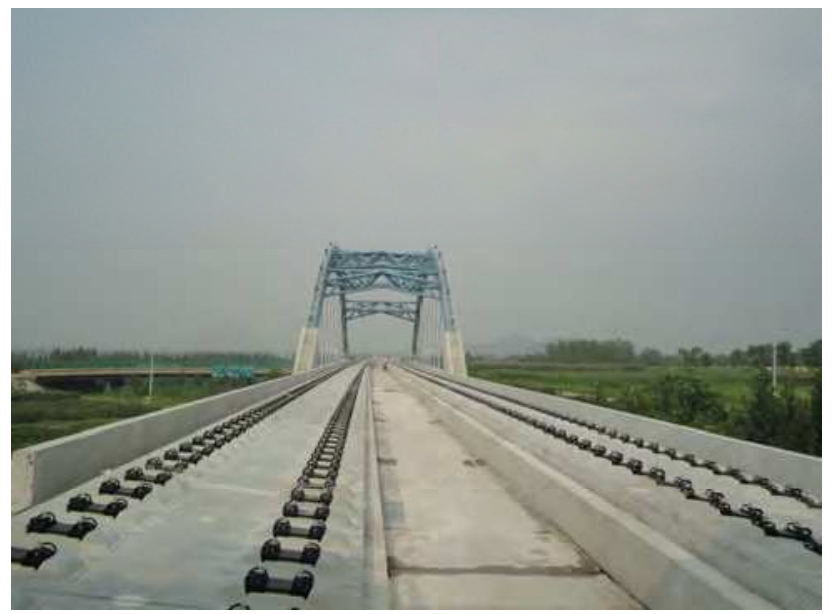

Fig. 38. Grouting finish 
The Compatibility and Preparation of

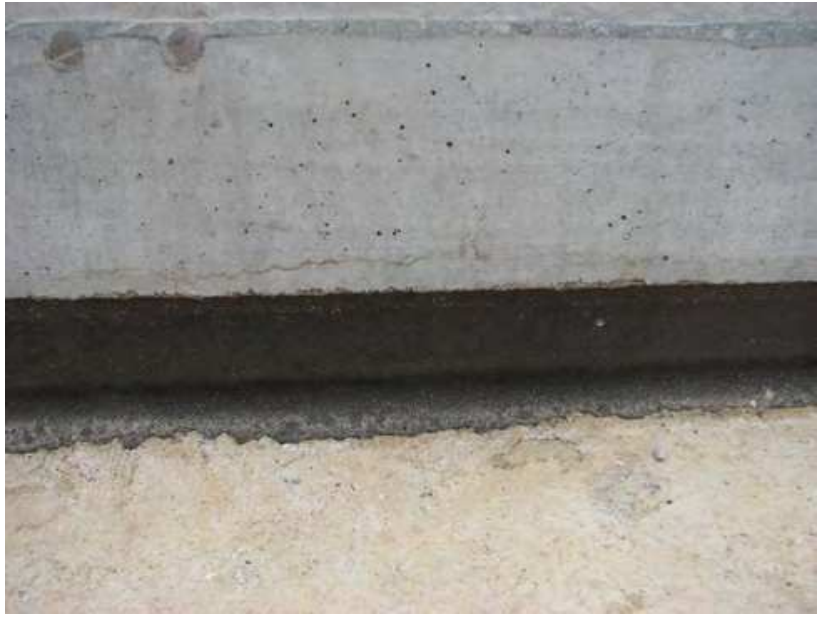

Fig. 39. Harden state of CA mortar

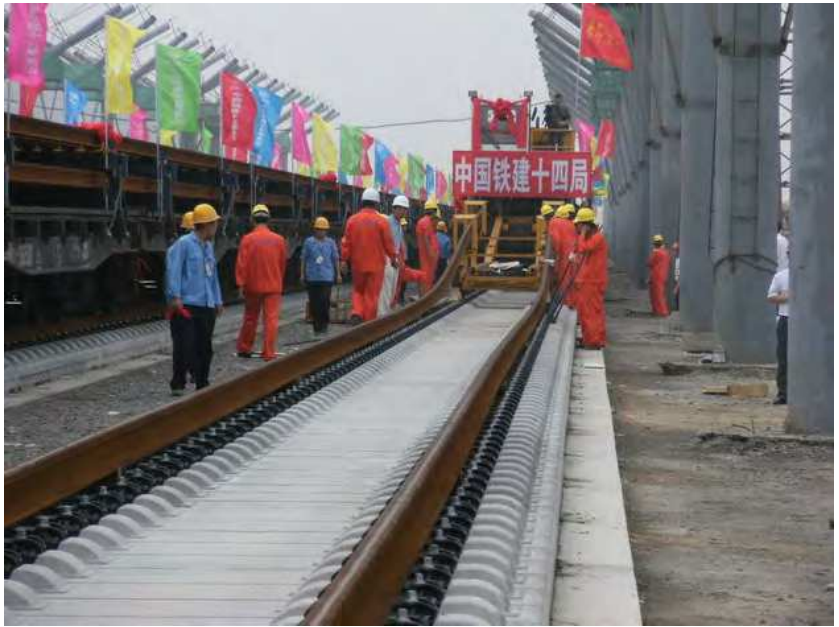

Fig. 40. Railway track laying 


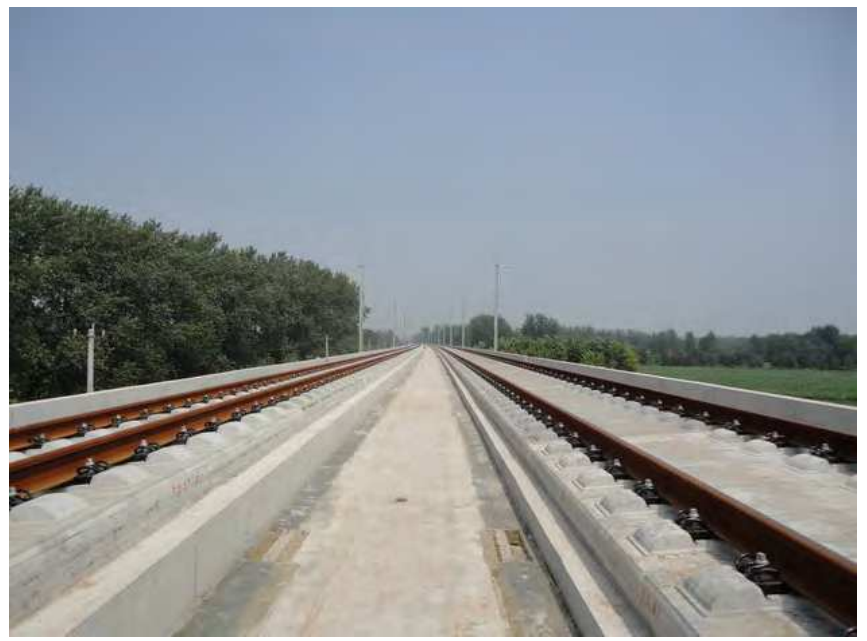

Fig. 41. Construction finish

\section{Acknowledgment}

The author would like to thank the National Natural Science Foundation of China (No. 50602033) and the Fundamental Research Funds for the Central Universities (No. 2010-II005) for the financial supports.

\section{References}

Al-Sabagh AM. (2002).The relevance HLB of surfactants on the stability of asphalt emulsion. Colloids and Surfaces A-Physicochemical and Engineering Aspects. Vol. 204, No.1-3, pp. 73-83.

A.S. Dukhin SSD, P.J. Goetz. (2007). Gravity as a factor of aggregative stability and coagulation. Advances in Colloid and Interface Science. No.133-135, pp.35-71.

Bury .M. Gerhards JE, W. Stamm, A. (1995).Application of a new method based on conductivity measurements to determine the creaming stability of $\mathrm{o} / \mathrm{w}$ emulsions. International Journal of Pharmaceutics. Vol.124, No.2, pp: 183-194.

Esveld C. (2003) .Recent development in slab track. European Railway Review, No. 2, pp: 8185.

Fazhou Wang, Yunpeng Liu, Yunhua Zhang, Shuguang Hu. (2012). Experimental study on the stability of asphalt emulsion for CA mortar by laser diffraction technique. Construction and Building Materials, No.28, pp.117-121.

Gullapalli RP, Sheth BB. (1996). Effect of methylcellulose on the stability of oil-in-water emulsions. International Journal of Pharmaceutics. Vol.140, No.1, pp. 97-109.

Harada Y TS, Itai N. (1983). Development of cement asphalt mortar for slab tracks in cold climate. Quart Rep RTRI (Railway Technical Research Institute), Vol.15, No.1, pp.62-67.

Harada Y TS, Itai N. (1976). Development of ultrarapid-hardening cement-asphalt mortar for grouted-ballast track structure. Quart Rep RTRI (Railway Technical Research Institute), Vol.17, No.1, pp.6-11. 
Hu SG, Wang T, Wang FZ, Liu ZC, Gao T. (2009) .Adsorption behavior between cement and asphalt emulsion in CA mortar. Advanced Cement Research, Vol.21, No.1, pp. 11-14.

Hu SG, Wang T, Wang FZ, Liu ZC, etc. (2009). Freezing and thawing resistance of cement asphalt mortar. Key Engineering Materials, No.400-402, pp.163-167.

Ivanov IB, Kralchevsky PA. (1997).Stability of emulsions under equilibrium and dynamic conditions. Colloids and Surfaces A: Physicochemical and Engineering Aspects. Vol. 128, No.1-3, pp. 155-175.

Ivanova R, Balinov B, Sedev R, Exerowa D. (1999). Formation of a stable, highly concentrated $\mathrm{O} / \mathrm{W}$ emulsion modeled by means of foam films. Colloids and Surfaces A: Physicochemical and Engineering Aspects. Vol.149, No.1-3, pp. 23-28.

Jin SH, C XF, Yang J. (2006). Key technologies of CA mortar for slab track. China Railway Science, Vol.27, No.2, pp.20-25. (In Chinese)

Kulmyrzaev A, Chanamai R, McClements DJ. (2000). Influence of $\mathrm{pH}$ and $\mathrm{CaCl}_{2}$ on the stability of dilute whey protein stabilized emulsions. Food Research International. Vol. 33, No.1, pp.15-20.

Li G., Zhao Y., Pang S.-S, Huang W. (1998).Experimental study of cement-asphalt emulsion composite. Cement Concrete Research, Vol.28, No.05, pp.635-641.

Masood, Irshad, Agarwal, S.K., Sinha, U.N. (1994).Effect of various admixtures on the particle size distribution of cement determined with the aid of laser particle analyzer. Cement Concrete Research, Vol.24, No.3, pp.527-532.

Miura S, Takai H, Uchida M. and Fukada Y. (1983) .The mechanism of railway tracks. Japan Railway \& Transport Review, No. 3, pp.38-45.

Ostberg GB, Bjorn; Hulden, Margareta. (1994). Mechanical Stability of Alkyd Emulsions. The Journal of Coatings Technology, No. 66, pp.37-46.

Pouliot N., Marchand J.,Pigeon M.(2003).Hydration mechanisms, microstructure, and mechanical properties of mortars prepared with mixed binder cement slurryasphalt emulsion. J Mater Civil Engng, No.1-2, pp. 54-59.

Song H., Do J., Soh Y. (2006).Feasibility study of asphalt-modified mortars using asphalt emulsion. Construction and Building Materials, No.20, pp. 332-337.

Supratim Ghosh JNC.(2008).Factors affecting the freeze-thaw stability of emulsions. Food Hydrocolloids, No.22,pp.105-111.

Su,Z., Bijen,J.M.J.M, Fraaij,A.L.A. (1993). Interaction of polymer dispersions with Portland cement paste. Mater Res Soc Symp Proc, No.289, pp. 199-204.

Vogel W. (1995). Earthwork structures for new railway lines slab track-Principles and suggestions for realization. Railway Technical Review, No.1, pp. 324 430.

Wang FZ, Wang T, Hu SG, Liu ZC, Gaotao, Chen Liang. (2008). Rheological behaviour of cement asphalt mortar. Engineering Journal of Wuhan University, Vol.41, No.4, pp.06 27. (In Chinese)

Wang FZ, Liu ZC, Wang T, Hu SG. (2008) .A novel method to evaluate the setting process of cement and asphalt emulsion in CA mortar. Materials and Structures, Vol.41, No.4, pp.643-647.

Wang FZ, Liu ZC, Wang T, Hu SG.(2010).Temperature stability of compressive strength of cement asphalt mortar. ACI Mater J, Vol.107, No.1, pp.27-30.

Wang FZ, Liu ZC, Hu SG.(2009). Early age volume change of cement asphalt mortar in the presence of aluminum powder. Materials and Structures, Vol. 43, No.4, pp.493-498. 
Wang FZ, Zhang YH, Liu YP, Tao T, Zou JZ, Chen L .(2009).Preliminary study on asphalt emulsion used in CA mortar. J Test Evaluation, Vol.37, No.5, pp.483-5.

Yunpeng Liu, Fazhou Wang.(2011).Influence of temperature on the absorption behaviour between cement and asphalt emulsion in CA mortar. Advanced Materials Research, No. 295-297, pp. 939-944.

Zuo JQ, Cai BF. (2005). Experimental research on the asphalt emulsion special for CA mortar in slab track. Railway Construction, No.2, pp.68-70. (In Chinese)

Zuo JQ, Fu DZ. (2005). Research on CA mortar in slab track. Railway Construction, No. 20, pp. 96-98. (In Chinese) 


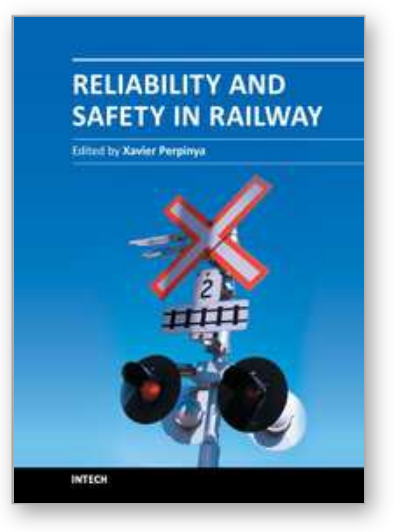

\author{
Reliability and Safety in Railway \\ Edited by Dr. Xavier Perpinya
}

ISBN 978-953-51-0451-3

Hard cover, 418 pages

Publisher InTech

Published online 30, March, 2012

Published in print edition March, 2012

In railway applications, performance studies are fundamental to increase the lifetime of railway systems. One of their main goals is verifying whether their working conditions are reliable and safety. This task not only takes into account the analysis of the whole traction chain, but also requires ensuring that the railway infrastructure is properly working. Therefore, several tests for detecting any dysfunctions on their proper operation have been developed. This book covers this topic, introducing the reader to railway traction fundamentals, providing some ideas on safety and reliability issues, and experimental approaches to detect any of these dysfunctions. The objective of the book is to serve as a valuable reference for students, educators, scientists, faculty members, researchers, and engineers.

\title{
How to reference
}

In order to correctly reference this scholarly work, feel free to copy and paste the following:

Fazhou Wang and Yunpeng Liu (2012). The Compatibility and Preparation of the Key Components for Cement and Asphalt Mortar in High-Speed Railway, Reliability and Safety in Railway, Dr. Xavier Perpinya (Ed.), ISBN: 978-953-51-0451-3, InTech, Available from: http://www.intechopen.com/books/reliability-and-safety-inrailway/the-compatibility-and-preparation-of-the-key-components-for-cement-and-asphalt-mortar-in-highspeed-

\section{INTECH}

open science | open minds

\author{
InTech Europe \\ University Campus STeP Ri \\ Slavka Krautzeka 83/A \\ 51000 Rijeka, Croatia \\ Phone: +385 (51) 770447 \\ Fax: +385 (51) 686166 \\ www.intechopen.com
}

\author{
InTech China \\ Unit 405, Office Block, Hotel Equatorial Shanghai \\ No.65, Yan An Road (West), Shanghai, 200040, China \\ 中国上海市延安西路65号上海国际贵都大饭店办公楼405单元 \\ Phone: +86-21-62489820 \\ Fax: +86-21-62489821
}


(C) 2012 The Author(s). Licensee IntechOpen. This is an open access article distributed under the terms of the Creative Commons Attribution 3.0 License, which permits unrestricted use, distribution, and reproduction in any medium, provided the original work is properly cited. 